\title{
DYSPLASIA EPIPHYSIALIS HEMIMELICA
}

\author{
(Tarso-epiphysial Aclasis)
}

\section{T. J. Fairbank, Cambridge, England}

This rare epiphysial dysplasia was first recognised and described as a definite entity by Trevor (1950), who collected ten cases and gave it the name of tarso-epiphysial aclasis. The only previously recorded case was that of Mouchet and Belot (1926) under the title of " tarsomégalie." Since Trevor's paper, only two further cases have been reported in the literature. One was recognised and given the title "chondrodystrophie épiphysaire" by Ingelrans and Lacheretz (1953). The medial side of the lower limb was involved in a boy of one and a half years. Both epiphyses at the knee, the medial malleolus, talus, navicular and first cuneiform were affected. The lesser trochanter, but not the femoral head, was also involved. Ossification in the centres for the navicular and first cuneiform were abnormally advanced. They regarded the condition as "a congenital dystrophy affecting the epiphyses and short bones of one ray of the limb." The second case, described by Donaldson et al. (1953) as " an osteochondroma of the distal femoral epiphysis," affected a girl of nine months. The inner side was involved; no other joints were radiographed, but the appearance of the knee is typical of the condition under discussion.

There is no doubt about the rarity of the condition. Enquiry at most of the orthopaedic centres in this country has produced only a total of fourteen further cases, including two in the upper limb which appear to fall into this group. The radiological appearances are sufficiently typical to make it unlikely that many examples would remain unrecognised. This communication embodies a report on this new material and a study of the total of twenty-seven cases which have now been recorded.

\section{NOMENCLATURE}

There are only three conditions so far known in which the primary defect lies in the epiphyses-dysplasia epiphysialis multiplex, dysplasia epiphysialis punctata, and the condition under discussion. It is true that the epiphyses may be involved in a number of other diseases, particularly in the Morquio-Brailsford type of chondro-osteo-dystrophy, but they are only a part, often inconstant, of the general pathological picture. It is the fate of newly recognised conditions to receive a succession of baptisms as the entity becomes better understood. There is no evidence to justify labelling this condition a dystrophy, as suggested by Ingelrans and Lacheretz, nor does the question of " rays" arise, as embryologically these are confined to the hand or foot and there is no counterpart in the more proximal segments of the limb.

Tarso-epiphysial aclasis, the name formulated by Trevor, is in the writer's view unsatisfactory for two reasons. First, although the tarsus is the most common site it is not constantly involved, even in cases affecting the lower limb. Nor need we consider the development of the tarsal bones as being basically in any way different from that of an individual epiphysis: the epiphysial plate peculiar to the latter is with very few exceptions unaffected in this condition. Furthermore it now appears that the condition is not even a monopoly of the lower limb, so that it seems to the writer no longer desirable to include the word "tarsus" in the title. Secondly, there is not simple failure of the perichondrium, where present, to model the epiphysis-that is, aclasis-but a true dysplasia or faulty growth of part of the epiphysis itself. It is true that even the unaffected side of the epiphysis is often slightly enlarged and abnormal in texture or outline. The whole upper femoral epiphysis was enlarged in Evans's case, reported by Trevor, and in Wainwright's case (Case 7 of this series) 
the medial side of the talus and navicular is possibly involved although the affection was otherwise confined to the outer aspect of the limb. These are the exceptions and may be secondary manifestations. The condition, according to our present experience, however, is in general confined to the lateral or medial half of a single limb, and for these reasons the name " dysplasia epiphysialis hemimelica" is suggested.

\section{HEREDITY AND FAMILIAL INFLUENCES}

In no instance has a parent or sibling been similarly affected. It is noteworthy that the patient reported by Donaldson et al. (1953) was a uniovular twin, the other twin being reported as normal. "Typical exostoses" were reported present in the case of Ingelrans and Lacheretz, and a cousin of James's patient is said to have a Sprengel's shoulder, but no other associated congenital abnormalities have been noted.

Sex-Males predominate, only seven of the twenty-seven patients being girls.

Age-The youngest subject was eight months old at the times of diagnosis, the oldest twentythree years. The majority first came under observation between the ages of two and eight.

\section{SYMPTOMS AND SIGNS}

Right and left sides are affected almost equally. The most common complaint in an otherwise healthy and normally developed child is of increasing swelling over the inner or outer aspect of knee or ankle. The swelling feels bony in consistency; the soft parts are not involved. When the inner side of the limb is affected, the mother may complain that the child is becoming knock-kneed or flat-footed in one leg, the reverse deformity being seen when the outer side of the joints is affected. The child may fall unduly frequently and there may be limitation of movement at the knee, ankle or tarsus. In one instance the knee " locked" in extension or flexion according to whether the medial ligament lay in front of or behind the prominence on the medial femoral condyle. Evans's patient, reported by Trevor, later developed painful " locking" incidents in the knee. The one adult patient also had symptoms of internal derangement of the knee.

There is occasionally pain in the ankle region, and there may be some secondary wasting of the muscles of the leg, but disability is minimal. The length of the limb is usually unaffected; in James's case (Case 4) there was a quarter of an inch of shortening, and in Brailsford's case (Case 3) there was a quarter of an inch of lengthening which later increased to one inch, part of this being due to coxa valga and a long femoral neck. Evans's patient developed half an inch of lengthening of the tibia. In one case the affected foot was markedly bigger than the other. Blood analyses have been consistently negative.

\section{DISTRIBUTION}

Characteristically the epiphysial abnormalities are confined to one side of the affected limb; the medial side was affected in nineteen, the lateral in eight, one of the latter patients (Case 7) having possibly some changes on the medial side also. In no case was more than one limb affected. Examination of the films of Mr Donald Brown's patient mentioned in Trevor's postscript (1950) as a possible bilateral case reveals what is almost certainly Köhler's disease in the right foot, but no changes suggestive of dysplasia epiphysialis hemimelica; the left knee is, however, typical. Table I shows the distribution of the lesions affecting the lower limb. It will be seen that the upper end of the femur is rarely involved, but when there are changes here there are lesions at knee, ankle and tarsus. The lower femoral epiphysis and the talus are the most common sites. With a few exceptions changes at the knee were accompanied by changes at the ankle or in the tarsus. The cuboid and the second and third cuneiforms have not so far been seen affected, and it appears probable that the involvement of the calcaneum reported in two cases has been no more than secondary distortion from the talar abnormality. The lesser trochanter was affected in two cases. 
TABLE I

Distribution OF Lesions IN TWENTY-FIVE LOWER LimBS

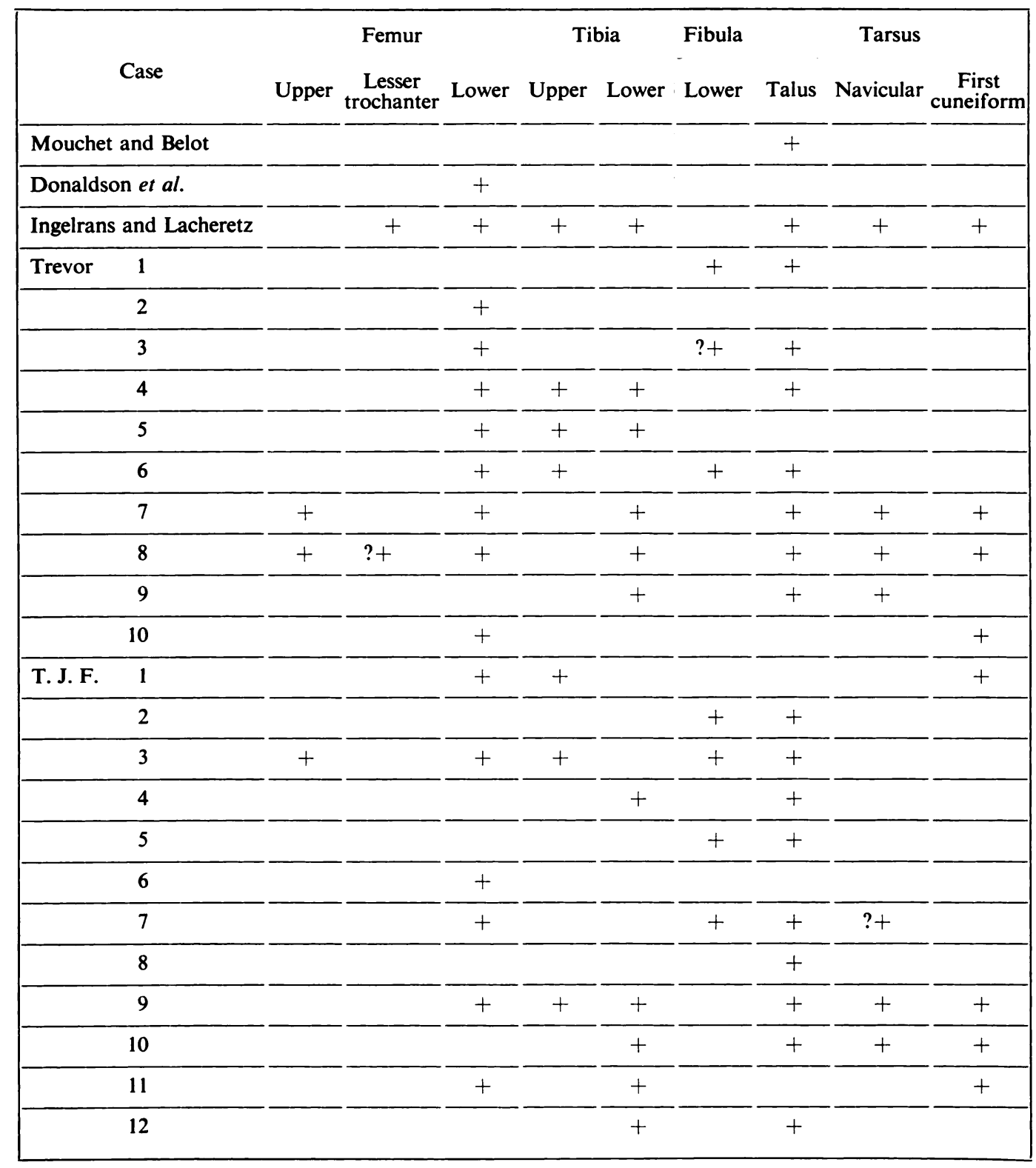

\section{RADIOLOGICAL APPEARANCES}

These are characteristic and have been admirably described by Trevor. Except in the case of the smaller tarsal bones, one side only of the epiphysis is involved. There may be generalised though irregular enlargement of the affected side, or more commonly there can be seen a number of separate centres of ossification, irregular in shape and size, discrete from the main epiphysis, and often so closely packed together that they appear to form a single mass of bone. From the lower femoral epiphysis they usually project sideways, downwards and backwards, but occasionally they lie in front of the coronal plane. As Trevor pointed out, one may see at the knee an anterior projection from the femoral epiphysis and posterior

VOL. 38 B, NO. 1, FEBRUARY 1956 
projection from the tibia, or vice versa. If the projection impinges on the opposing articular surface, varus or valgus deformity is produced, but large masses may be seen on radiographs projecting from the side and margin of the epiphysis without causing any angular deformity whatever. In young subjects these secondary centres are often widely separated from their parent epiphyses, but with the passage of time they tend to fuse with each other and then with the main body of the epiphysis, although this does not always occur (Case 9). Secondary deformation in the opposing epiphysis at a joint is not uncommon.

The metaphysis is in general unaffected, but in two cases there was considerable widening of the femoral neck with, in one instance, elongation of the neck and coxa valga; and in two examples changes in the lower fibular epiphysis were associated with quite marked widening of the metaphysial region. The length of the bones is usually unaltered, but exceptions have already been quoted. No bowing of the shaft of a long bone has been seen, except in the ulna in Case 13, which also underwent progressive shortening.

When the tarsus is involved there may be massive enlargement of the body of the talus, the articular surface of which sometimes appears crenated in the antero-posterior view, and the whole bone may be tilted to one side or the other. Even when the whole body is enlarged it is obvious that one side is much more severely affected than the other. There is little or no diastasis of the tibio-fibular mortise. The head of the talus is less often involved than the body, but it was noteworthy that in several cases the head had lost its normal rounded contour and had become almost square in outline on the lateral view. The navicular and first cuneiform are commonly included in the process, but not the other tarsal bones. In cases seen early enough there is premature appearance of the bony centres for the tarsal bones, particularly when the medial side of the foot is involved, and these centres remain larger than their fellows in the opposite foot for several years. Slight increase in length of the medial metatarsals has also been observed. These last two points were considered of some importance in placing Freebody's case (Case 12) into the group, as there was enlargement of the centres for both multangular bones and lengthening of the second metacarpal. The upper fibular epiphysis and that for the patella have not been seen involved.

The whole skeleton has been radiographed in many of the cases reported here, and no abnormalities elsewhere have been detected.

\section{PROGRESS}

The swelling increases gradually for the first few years of life, and varus or valgus deformity at a joint may appear or increase during this period. After the age of six or seven there may be little deterioration, the swelling increasing only pari passu with the general growth of the child. Radiologically new centres of ossification may appear, and the multiple bony centres increase in size and tend to fuse together into a common mass which itself usually fuses with the rest of the epiphysis, where changes in texture in the affected region overshadow the previously clear-cut division between the normal and abnormal epiphysial bone. When the projection is a long one and movements put a strain on its junction with the rest of the epiphysis it appears that sometimes part or all of the projection is broken off, union of the fractured cartilage fails to occur, and a fragment remains permanently separated from the rest of the epiphysis by attenuated fibrous tissue or even a false joint. No elderly patients have yet come under observation but one must presume that many of the misshapen joints will be liable to later degenerative arthritis.

\section{TREATMENT}

Part or all of the outgrowth has been removed in a number of patients with benefit in every case. When there had been valgus or varus deformity from the pressure of the outgrowth this was improved or completely corrected. Apart from cosmetic interventions, this appears to be the main indication for operation. Although post-operative radiographs often show that a considerable proportion of the affected part of the epiphysis has been left untouched 
no ill-effects have resulted, no attempt at regeneration of the excised portion takes place, and normal and remaining abnormal parts of the epiphysis continue to grow as if there had been no intervention. There are, however, many cases, particularly those involving the body of the talus, in which it is obvious that any corrective procedure would involve a prohibitively large removal of the bone. On two occasions adequate removal of the outgrowth at the knee so damaged the attachments of the semilunar cartilage that it had to be excised. At the knee a supracondylar osteotomy was done to correct genu valgum in two patients.

\section{PATHOLOGY}

At operation the outgrowth is found to be covered with glistening bluish cartilage similar to that of the normal epiphysis. Its surface may be smooth and its line of junction to the rest of the epiphysis indistinguishable. More often, however, its surface is irregular and slightly knobbly and a groove of varying depth demarcates it from the normal tissue. When a fragment has become entirely separated from the rest of the epiphysis it is found lying snugly fitting a bed lined with cartilage, to which it is attached by bands of fibrous tissue. In some areas movement has produced the appearance of a false joint.

Microscopically the appearances are like those of an osteochondroma. There is a thick zone of hyperplastic cartilage distinguishable from that of the rest of the epiphysis only by some irregularity of cell size and distribution. Active normal enchondral ossification is taking place around the bony centres, which are irregular in size and shape and may be rather deficient in marrow spaces, making the bone relatively dense. The bone itself shows otherwise no abnormality. There is therefore apparently no characteristic feature on which a diagnosis can be made from biopsy material.

\section{DIAGNOSIS}

While one may exceptionally detect so rare a condition clinically, diagnosis from radiographs is usually simple. The restriction of changes to those epiphyses or parts of epiphyses lying on one side of a single limb, the characteristics of those changes, and the absence of abnormalities in other parts of the skeleton permit no alternative diagnosis. The other epiphysial dysplasias are different in a host of ways. Synovial osteochondromatosis may produce somewhat similar radiological appearances, but the patient is older and the epiphysial regions are unaffected. Cases have been seen in which a single bony outgrowth from some tarsal bone caused suspicion of the condition, but in the present state of our knowledge it has been considered wiser not to include them in this group, although they may be closely related.

\section{ETIOLOGY}

It is fascinating, though perhaps profitless, to delve into the possible causes of this condition. We can be fairly sure that the cause, whatever it may be, is active early in the fifth week of foetal development. The limb bud for the arm first appears on the twenty-sixth day, for the leg on the twenty-eighth day. We know (Duraiswami 1952) that insulin and a number of other substances can produce multiple abnormalities of the limbs which vary in distribution largely according to the exact time at which they are introduced into a chick embryo. Most of the experimental work on the production of monomelic abnormalities has been done on chicks or on amphibia, but there is reason to believe that we can safely apply the results of such experiments to mammalia. Saunders (1948) has shown how the orderly sequence in which the parts of the chick's wing develop proximo-distally is controlled by the apical ectoderm of the limb bud; extirpation of this apical cap suppresses further distal development of the wing. If it is done on the third day the entire wing is suppressed. If extirpation is delayed for a few hours, growth of the humerus proceeds normally but nothing distal to it, and so on. Within a single day, even though.the.limb.has grown little in size, it has developed all the basic cells destined to form the entire limb, and damage to the apical ectoderm after this stage will not prevent the normal development of the limb. When the upper limb apical

VOL. 38 B, NO. 1, FEBRUARY 1956

$Q_{(\times)}$ 
growth zone with its ectodermal cap is grafted to the stump of a leg bud typical wing parts are formed appended to the proximal leg structures. If only the pre-axial part of the apex of the early wing bud is extirpated a wing develops lacking the pre-axial element of the humerus, and minus a radius and the radial half of the carpus, metacarpus and phalanges. Agenesis of the ulnar side of the wing follows removal of the post-axial half of the apical cap. Tschumi (1954), working with Xenopus larvae (a variety of toad), investigated the effect of local application of dilute nitrogen mustards to the limb bud and produced various growth abnormalities, particularly in the metacarpus.

Streeter (1930), in his work on intra-uterine amputations and other developmental abnormalities of the limbs, concluded that all are due to some local defect in the limb bud itself.

In dysplasia epiphysialis hemimelica we have no knowledge of what the primary fault may be, whether in the original germ-plasm, the "organisers" within the foetus, focal haemorrhages, "bleb" formation or any other of the many etiological factors that have been suggested; it may even be due to some cause outside the embryo itself. But we can be fairly sure that it affects either the pre-axial or post-axial part of the apical cap of a single limb bud, probably for a very short time and in a minute area, and that the localisation of the future lesions depends on the exact timing and site of this fault.

I am deeply indebted to all those who have so generously loaned the clinical notes and radiographs of their cases reported here, and to the many others who kindly searched their records for further examples although without avail. My special thanks are also due to Mr David Trevor and to those whose cases he reported in 1950 for making available to me the follow-up material on which the notes on "Progress" and "Treatment" were largely based. I am most grateful, too, to Professor J. D. Boyd and Dr P. Tschumi of the University Department of Anatomy at Cambridge for their willing assistance and advice on recent embryological developments, to Dr A. M. Barrett of the Department of Pathology for the photomicrographs and pathological reports, and to Miss Westoby at Addenbrooke's Hospital for the photographic work; and to $\mathrm{Mr}$ J. N. Aston for the operation sketch of Case 9. Finally I offer profound tribute and thanks to my father for his inspiration, his zest, and his unstinted guidance and help.

\section{REFERENCES}

Donaldson, J. S., Sankey, H. H., Girdany, B. R., and Donaldson, W. F. (1953): Osteochondroma of the Distal Femoral Epiphysis. Journal of Pediatrics, 43, 212.

Duraiswami, P. K. (1952): Experimental Causation of Congenital Skeletal Defects and its Significance in Orthopaedic Surgery. Journal of Bone and Joint Surgery, 34-B, 646.

Ingelrans, P., and Lacheretz, M. (1953): A propos d'un cas de chondrodystrophie épiphysaire. Revue de Chirurgie Orthopédique, 39, 242.

Mouchet, A., and Belot, J. (1926): La Tarsomégalie. Journal de Radiologie et d'Electrologie, 10, 289.

SAunders, J. W. (1948): The Proximo-Distal Sequence of Origin of the Parts of the Chick Wing and the Role of the Ectoderm. Journal of Experimental Zoology, 108, 363.

Streeter, G. L. (1930): Focal Deficiences in Fetal Tissues and their Relation to Intra-uterine Amputation. Contributions to Embryology, 22, No. 126. [Publication 414 of the Carnegie Institution of Washington.] Trevor, D. (1950): Tarso-Epiphysial Aclasis: a Congenital Error of Epiphysial Development. Journal of Bone and Joint Surgery, 32-B, 204.

Tschumi, P. (1954): Konkurrenzbedingte Rückbildungen der Hinterextremität von Xenopus nach Behandlung mit einem Chloraethylamin. Revue Suisse de Zoologie, 61, 177.

\section{APPENDIX}

DETAILS OF THIRTEEN COLLECTED CASES OF DYSPLASIA EPIPHYSIALIS HEMIMELICA

Case 1 (reported by courtesy of Mr A. L. Eyre-Brook)-Girl aged two years three months. Six months' history of frequent falls, with deformity of the right knee. There was bilateral genu valgum, more marked on the right. At operation the infero-posterior part of the medial femoral condyle was lumpy and rather bluer than the rest of the epiphysis. The greater part was cut away, correcting the genu valgum. The medial semilunar cartilage required removal. A skeletal survey showed lesions only in the medial side of both epiphyses at the knee and in the right first cuneiform (Figs. 1 and 2). Radiographs of the specimen are shown in Figure 3.

Case 2 (reported by courtesy of Mr D. Freebody)-Boy aged two years nine months. There had been pain and swelling of the outer side of the left ankle for one month after a fall. Similar trouble for a 


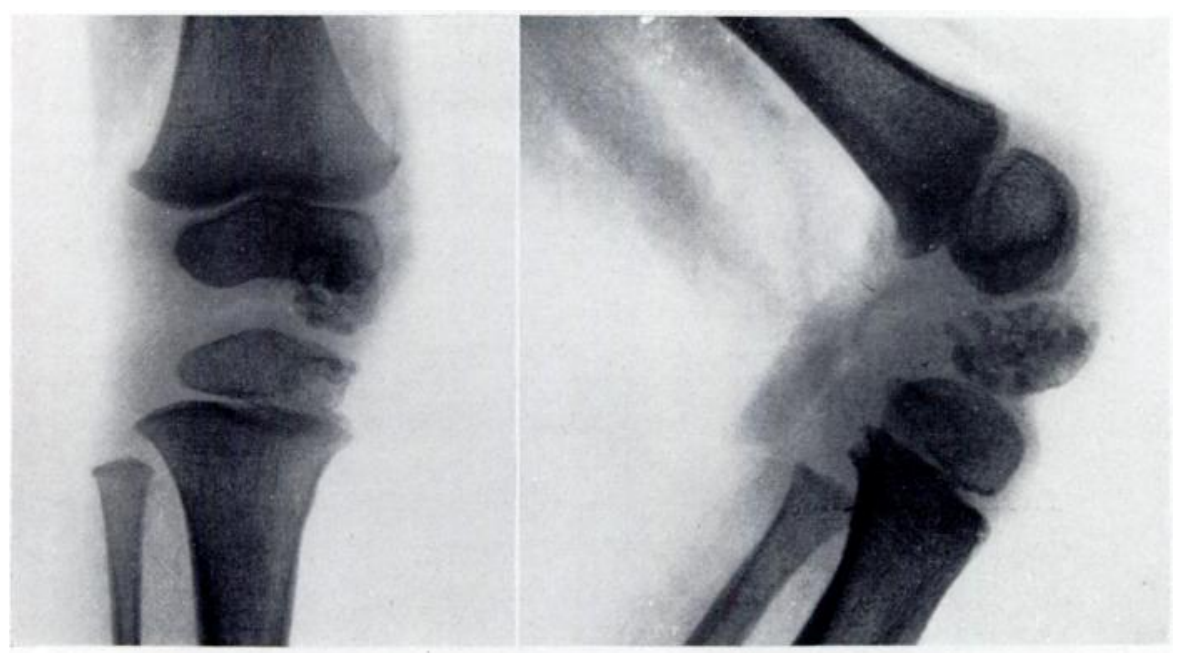

Fig. 1

Case 1-Right knee. The medial sides of both epiphyses are involved.

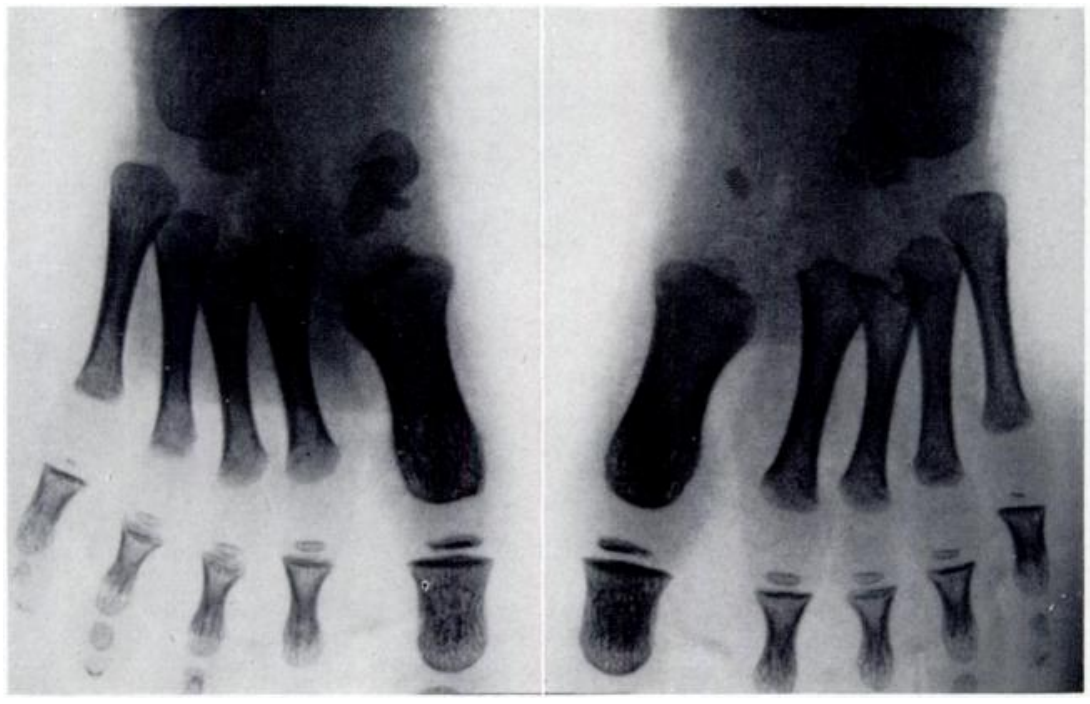

FIG. 2

Case 1-Feet. The right shows enlarged first cuneiform with multiple centres of ossification.

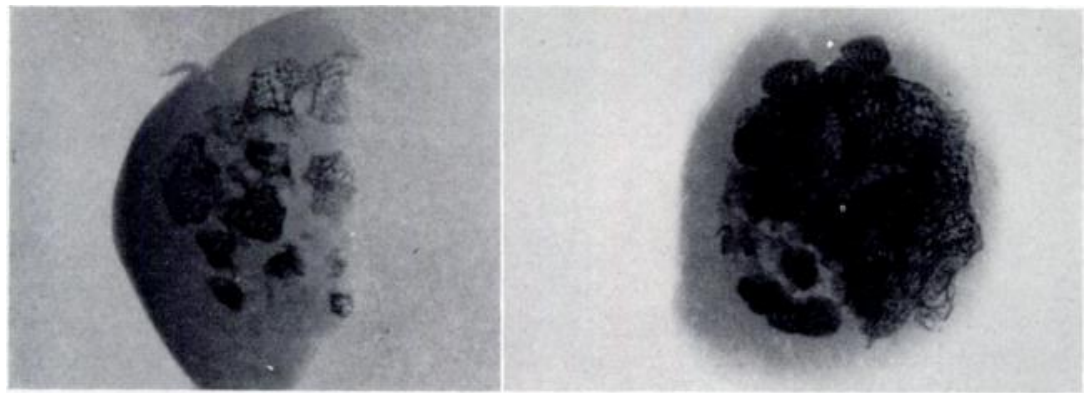

Fig. 3

Case 1-The specimen from the medial femoral condyle.

VOL. 38 B, NO. 1, FEBRUARY 1956 
few weeks one year previously, not associated with injury. Eversion of the foot, which was otherwise fully mobile, was blocked by a bony prominence below and in front of the lateral malleolus. Radiographs showed involvement of the outer side of the talus and of the inferior fibular epiphysis, the metaphysis of which was splayed out (Fig. 4). The centre for the navicular was much larger than in the right foot. At operation two bony fragments were found attached by fibrous tissue to the lateral aspect of the talus, one projecting into the sinus tarsi. They were removed, together with a third mass of cartilage and bone arising from the medial aspect of the lower fibular epiphysis. The child made an excellent recovery.

Case 3 (reported by courtesy of Dr J. F. Brailsford)-Boy aged five. Bowing of the right leg with a quarter-inch of lengthening. In the course of two years three months the shortening increased to one inch. Radiographs (Figs. 5 to 7) showed irregular enlargement of the lateral half of the femoral head, coxa valga and a long femoral neck, a multi-centred mass growing from the outer side of the lower femoral epiphysis, and slight changes in the upper tibial epiphysis laterally. At the ankle there was an outgrowth from the outer side of the body of the talus and a large mass of bone arising from the fibular epiphysis, causing considerable diastasis.
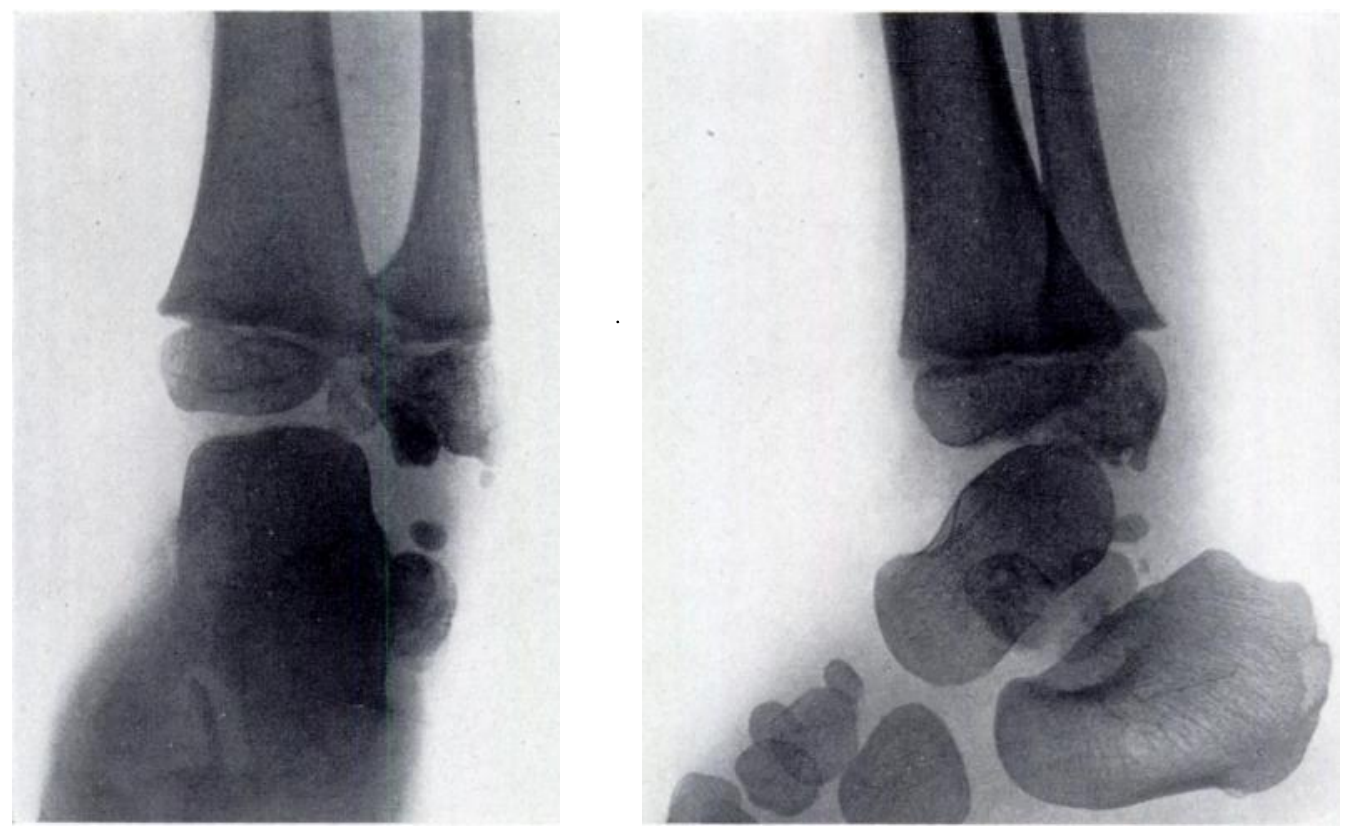

FIG. 4

Case 2-Left ankle, showing lesions of talus and fibular epiphysis, with splaying of the fibular metaphysis.

Case 4 (reported by courtesy of Mr J. I. P. James)-Boy aged eight years six months. At the age of eighteen months is said to have fractured his right ankle. Had been under observation elsewhere for the last three years and an operation performed to remove a bony prominence. The right medial malleolus was still extremely prominent, the ankle displaced laterally and the foot in slight valgus. Dorsiflexion was limited to 90 degrees. The right leg was underdeveloped and a quarter-inch shorter than the left. Hip and knee were normal. Radiographs (Fig. 8) showed irregular enlargement of the medial side of the talus, which projected forwards and also upwards into the medial half of the tibial epiphysis, where there appeared to be a secondary concavity. The medial malleolus was enlarged, and the navicular rather deeper than in the left foot. The patient has been kept under observation for five years, during which there has been little deterioration, the swelling increasing only pari passu with the growth of the child and the degree of valgus only increasing slightly (Fig. 9).

Case 5 (reported by courtesy of Mr K. I. Nissen)-Girl aged six years six months. History of painless swelling of the outer side of the left ankle for six months. There was a bony prominence in front of the outer part of the ankle, particularly in plantar flexion. There was some limitation of ankle and subtalar movements. Radiographs (Fig. 10) showed irregular enlargement of the outer half of the body of the talus, the head of which was flattened. The lower fibular epiphysis was elongated and bulbous in its distal part. Other joints were normal. 


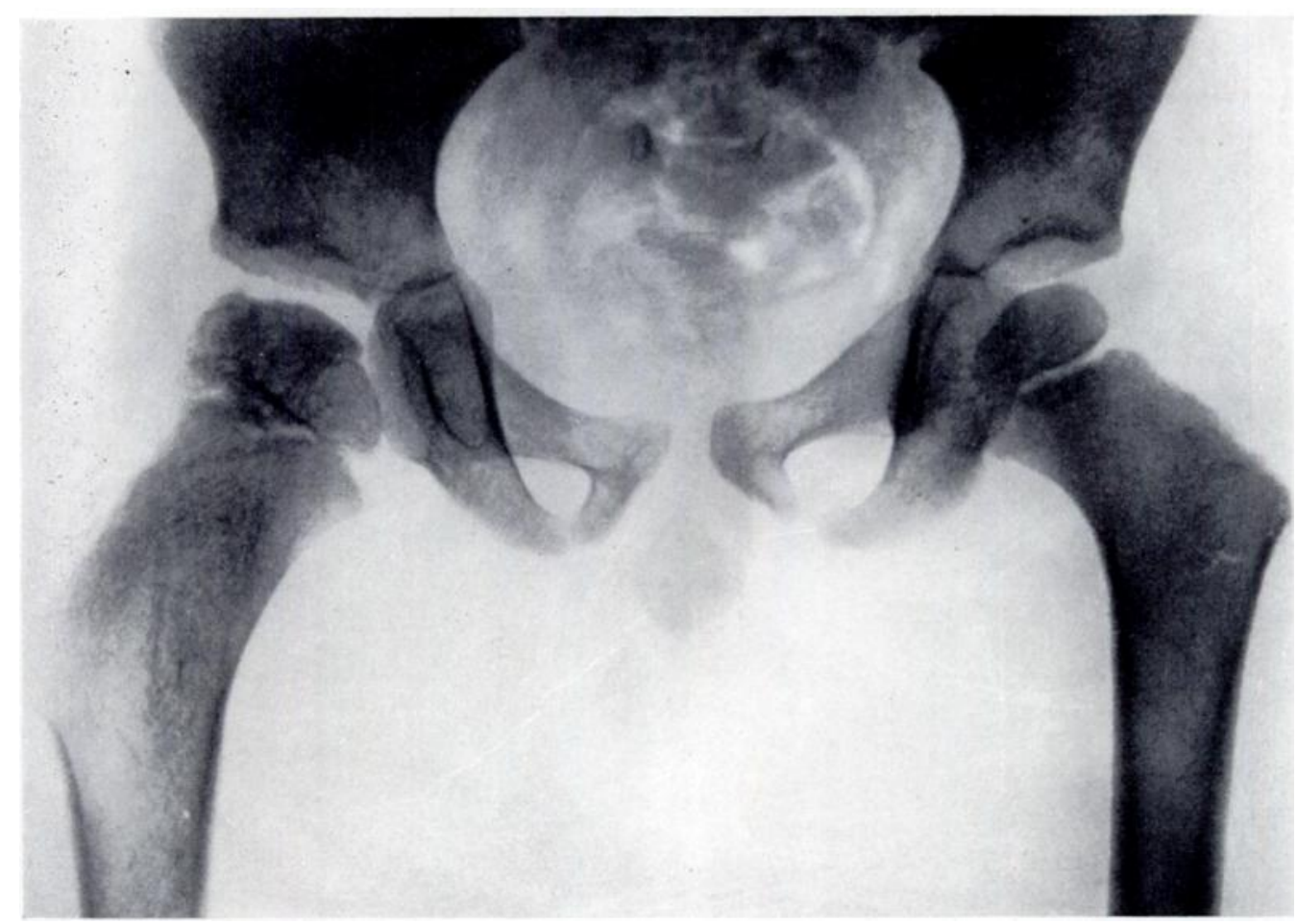

Fig. 5

Case 3-The outer part of the right upper femoral epiphysis is irregularly enlarged, and the femoral neck long, thick and valgus.

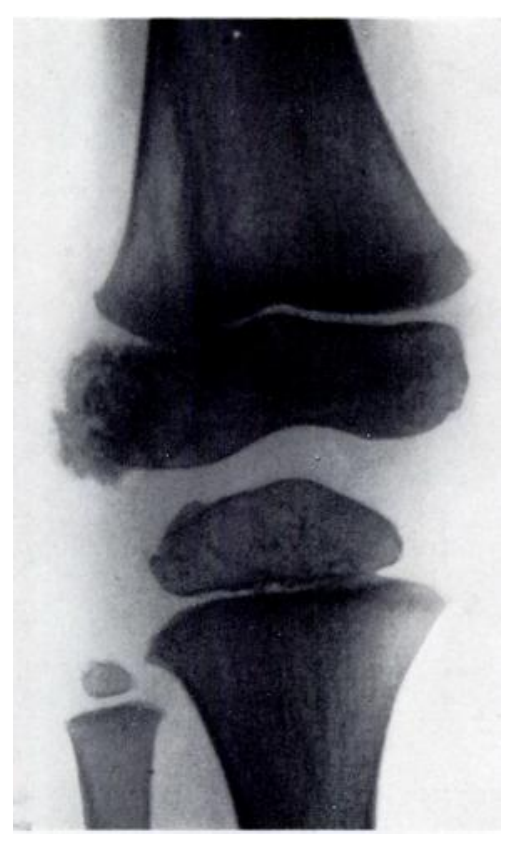

Fig. 6

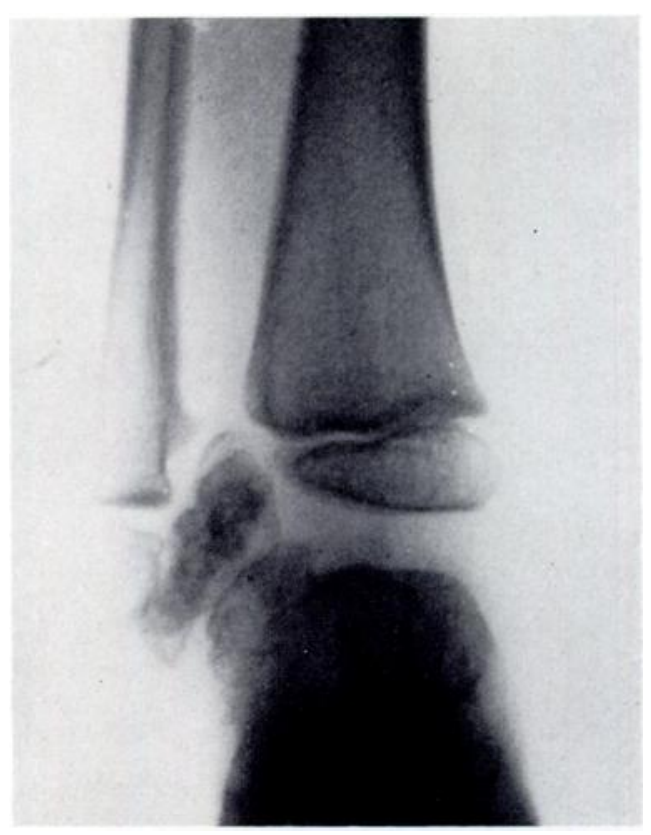

Fig. 7

Case 3. Figure 6-Right knee. The outer part of the tibial epiphysis is minimally affected. Figure 7Right ankle. Talus and fibular epiphysis are involved, upward growth from the latter apparently producing diastasis.

VOl. 38 B, NO. 1, februARY 1956

Q1 $1_{(4)}$ 

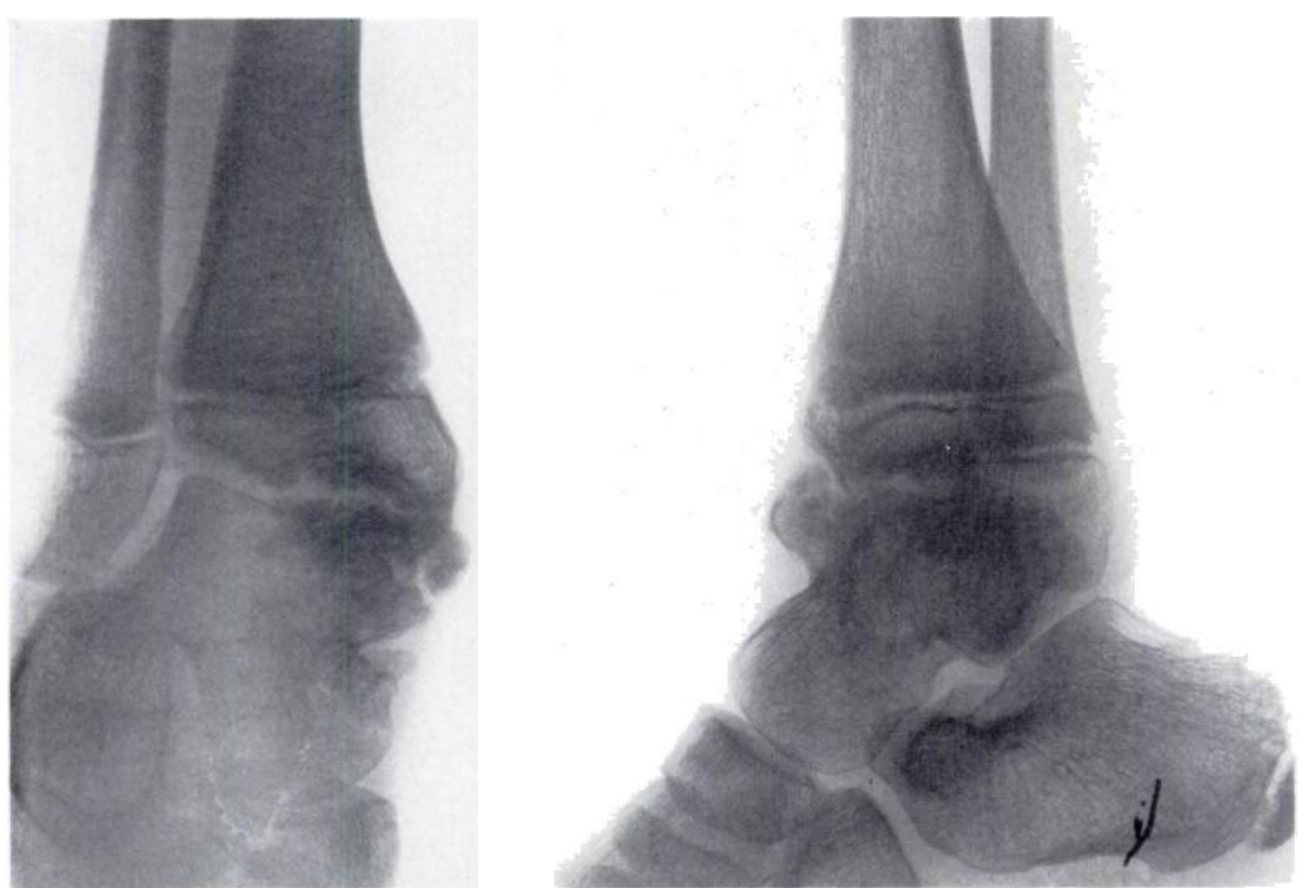

FIG. 8

Case 4 -Right ankle. The outgrowth from the talus has produced a cavity in the tibial epiphysis, which is itself affected.

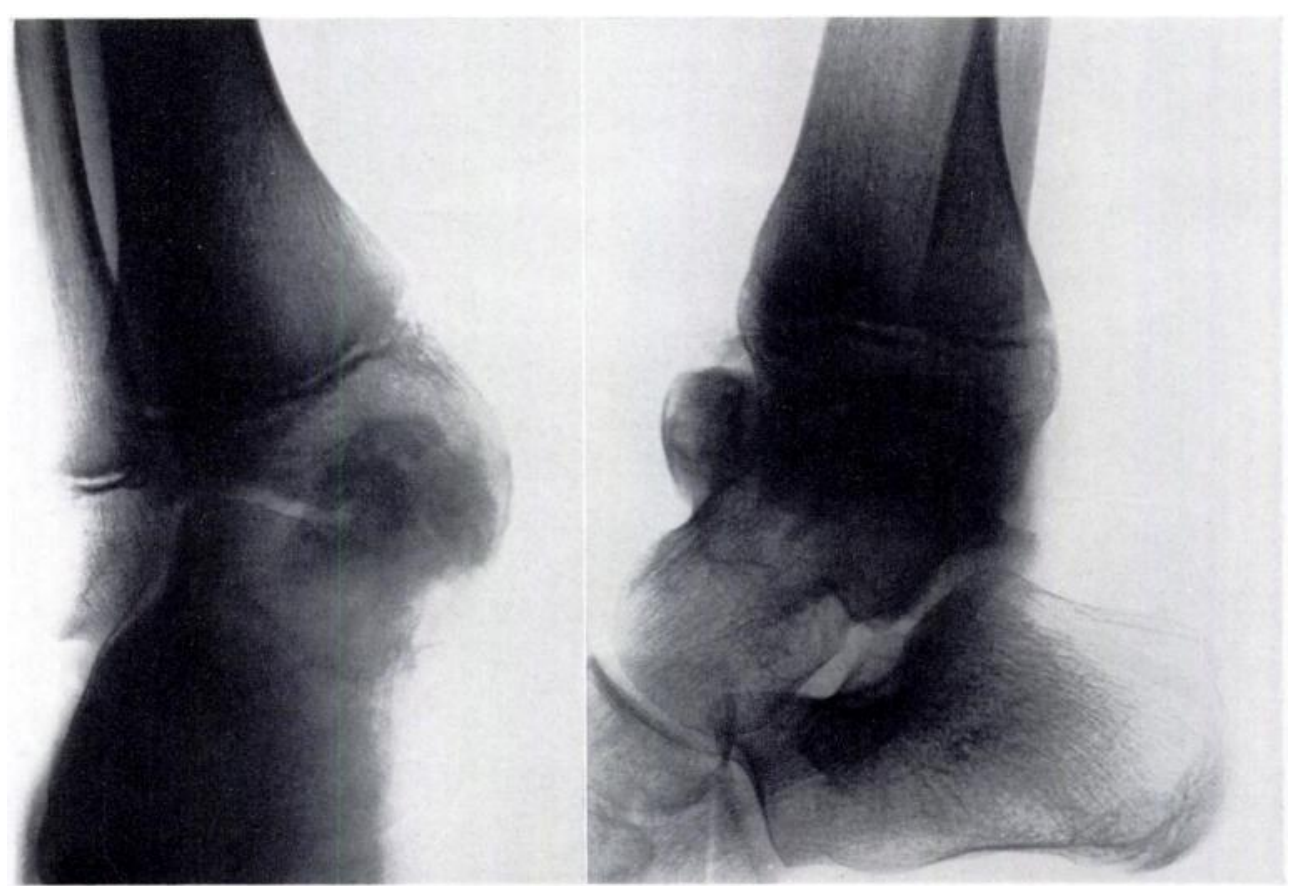

FiG. 9

Case 4-The same ankle four years later.

Case 6 (reported by courtesy of Mr David Trevor)—Boy aged three. Painless swelling of the inner side of the right knee noticed since a minor fall ten days previously. The swelling was bony hard; there was no restriction of movement. At birth he was said to have had a lateral rotation deformity of the right leg; this recovered spontaneously in six months. A cousin is said to have a Sprengel's shoulder. The swelling increased and genu valgum developed, and one year three months later the 


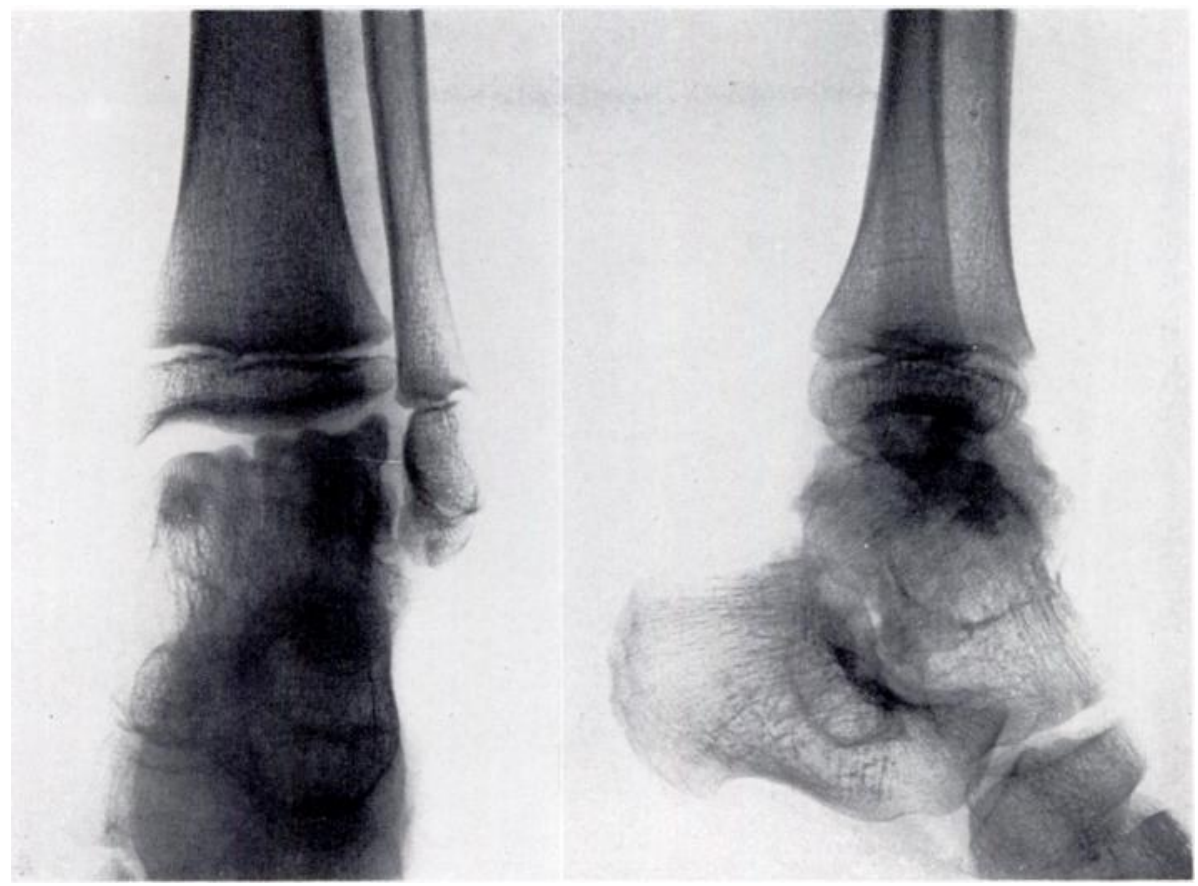

FIG. 10

Case 5-The ankle, fibula and outer part of talus involved. Note the flattening of the head of the talus.

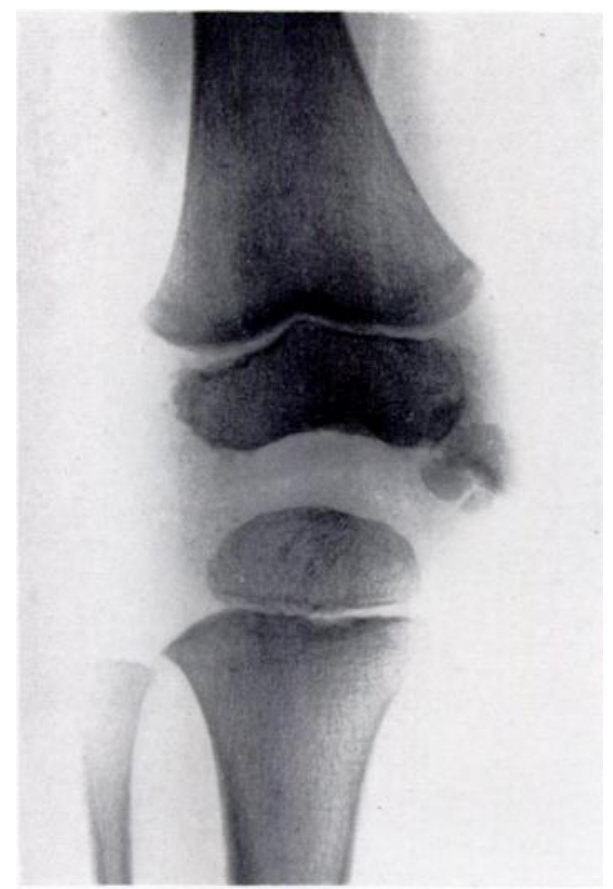

Fig. 11

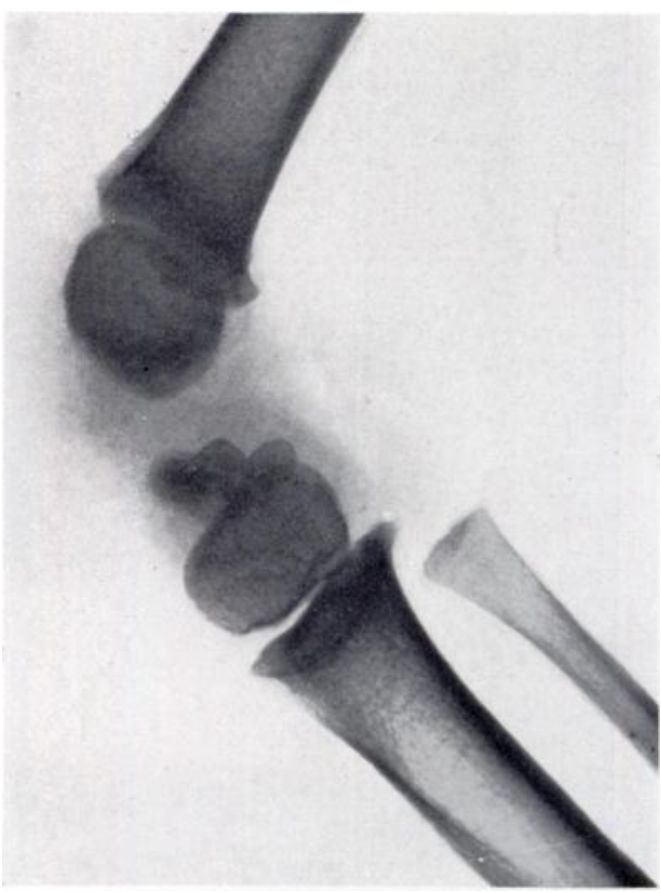

FIG. 12

Case 6. Figure 11-Involvement of the medial side of the femoral epiphysis. Figure 12-An earlier lateral view showing the wide separation of the new centres from the parent epiphysis.

VOL. 38 B, NO. 1, FEBRUARY 1956

Q2. 


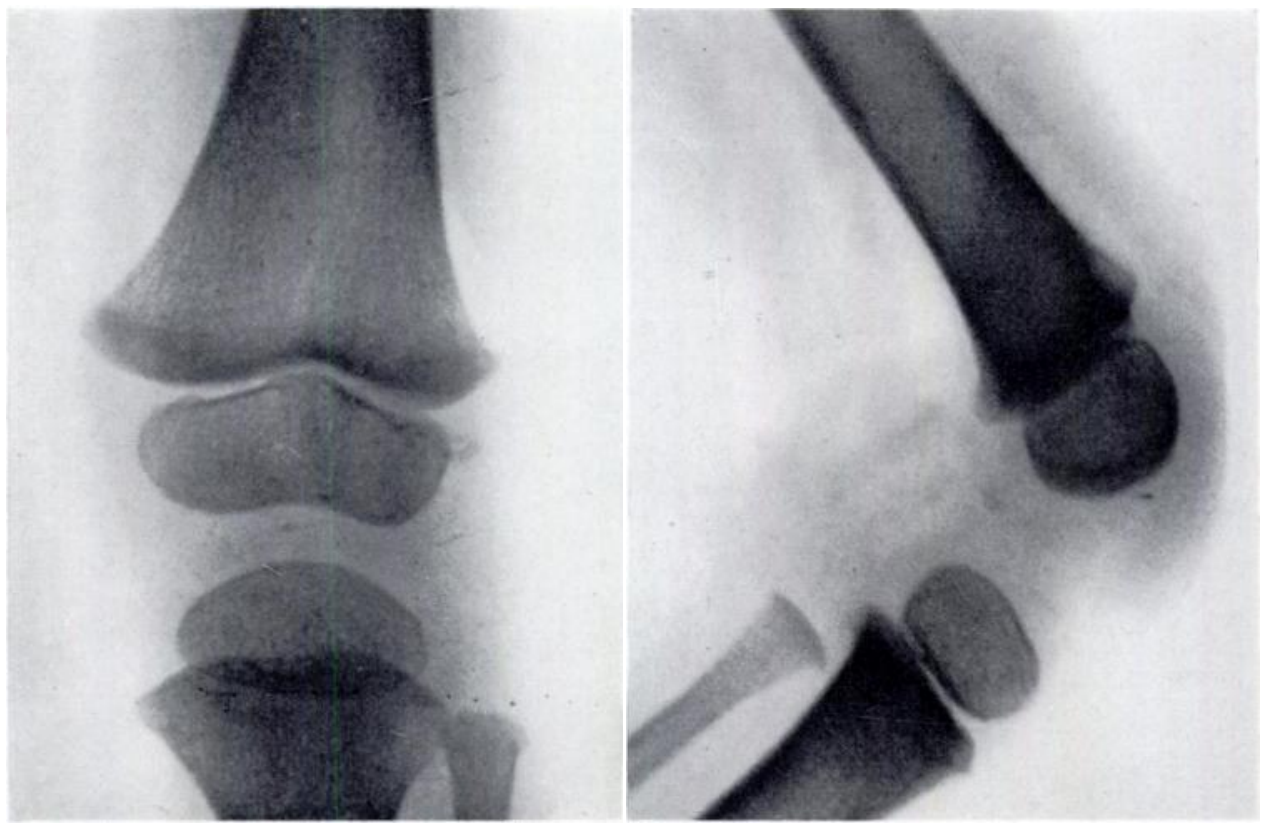

Fig. 13

Case 7-The knee, aged one year. A new centre is just visible behind the lateral femoral condyle.

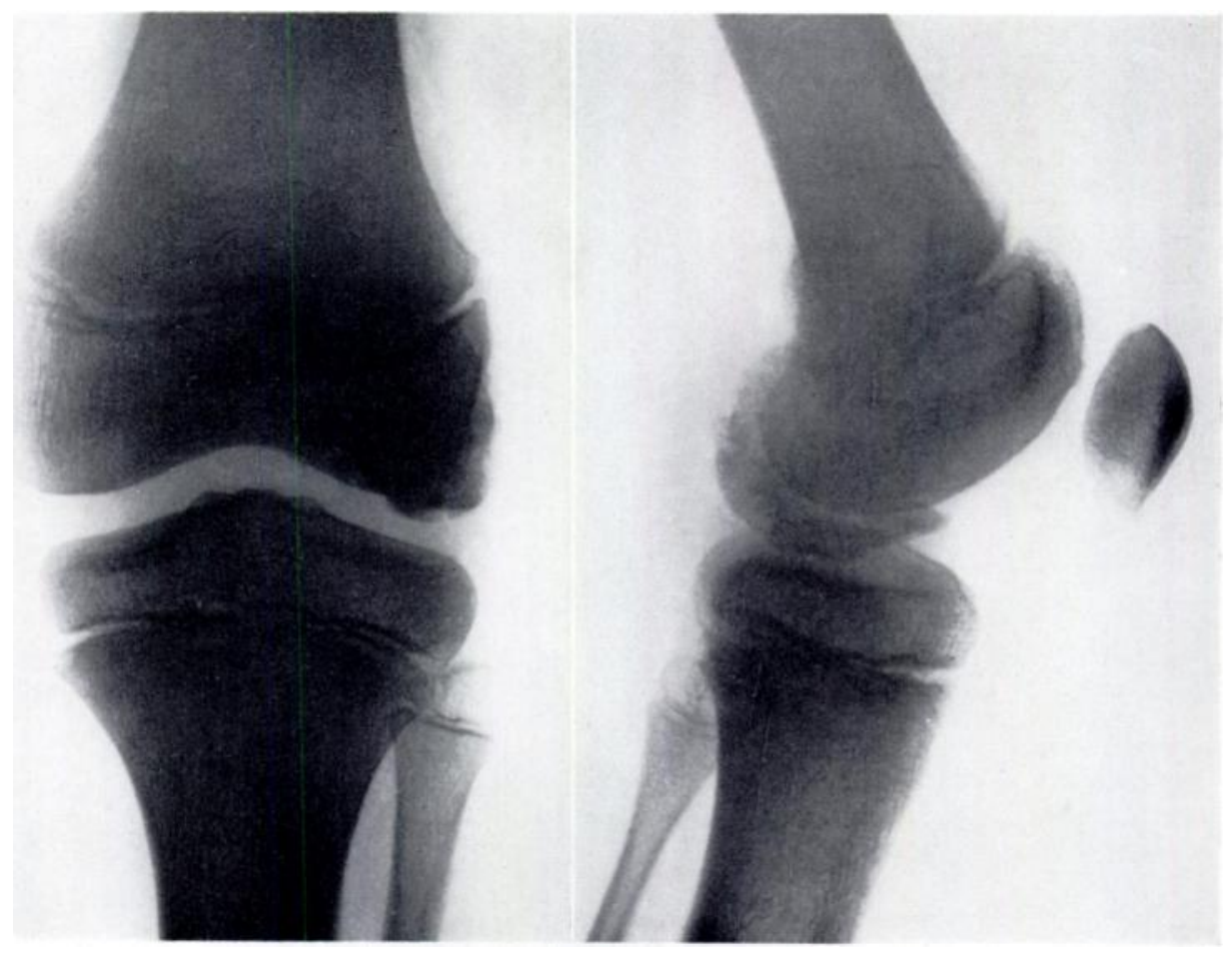

FIG. 14

Case 7-The same, nine years later.

THE JOURNAL OF BONE AND JOINT SURGERY 
greater part of the outgrowth was removed. Radiographs (Figs. 11 and 12) showed at least three separate centres of ossification lying below and behind the medial side of the femoral epiphysis. No other joint was affected.

Case 7 (reported by courtesy of Mr Denys Wainwright)-Boy aged ten. When one year old "went off his feet " for three weeks. Radiographs (Fig. 13) showed a small centre of ossification just visible behind and lateral to the outer side of the left lower femoral epiphysis. Attended aged ten complaining of pain in the left ankle which was thickened around the lateral malleolus; there was marked rigidity of the foot. Radiographs (Fig. 15) showed a bony mass below and in front of the lateral malleolus and another projecting from the back of the body of the talus. The head of the talus was flattened and the tubercle of the navicular was enlarged and irregular; this however may be analogous to a large os tibiale externum. The outer posterior part of the lower femoral epiphysis was now obviously involved (Fig. 14). The outgrowth from the lateral malleolus was removed.

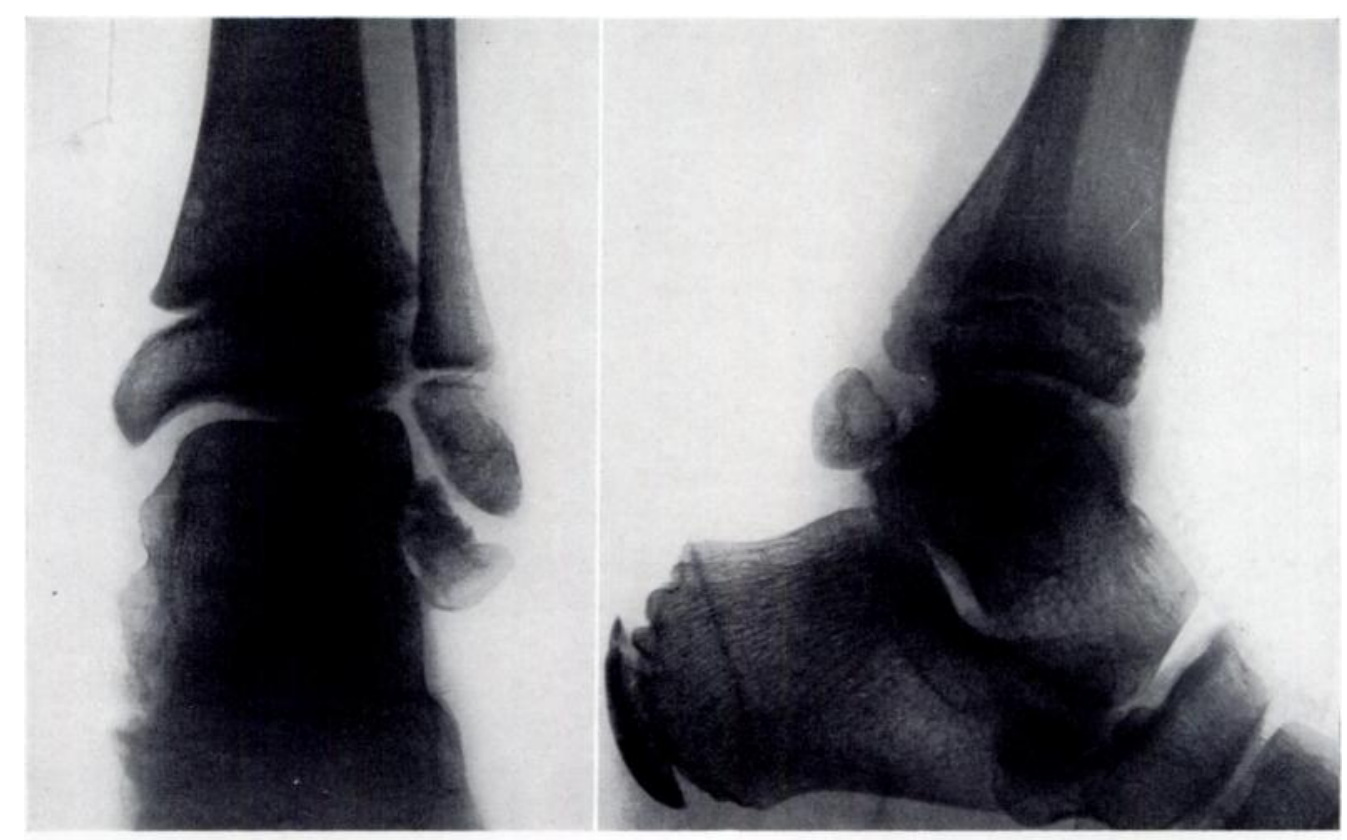

FIG. 15

Case 7-The ankle. Talus and lateral malleolus are involved; the head of the talus is flattened; the tubercle of the navicular is enlarged and irregular.

Case 8 (reported by courtesy of Mr F. C. Dwyer)-Boy aged five. Presented with valgus feet, limited inversion of the right foot and wasting of the right calf muscles. Radiographs (Fig. 16) showed an irregular outgrowth from the head and neck of the talus, a large ossification centre for the navicular (that on the left foot had not yet appeared) and slight lengthening of first and second metatarsals. Removal of the " exostosis" led to almost full recovery of the range of inversion.

Case 9 (reported by courtesy of Mr D. Ll. Griffiths)-Man aged twenty-three. He complained that for nine years his right knee had been increasingly liable to give way and lock in about 60 degrees of flexion, when he could feel a lump antero-medially. With rest this went down and movement recovered. Ten years previously he had had an operation on the right foot which had always " turned out ": this had relieved him. On examination the whole right lower limb was wasted. The medial tibial condyle was prominent. The knee joint was crepitant and lacked full extension; no rotary movement was possible. The foot was held in marked valgus. Ankle and tarsal movements were severely restricted; the talus was prominent in front of the medial malleolus. Radiographs (Fig. 17) showed that both epiphyses on the medial aspect of the knee had been involved and a large irregular mass of bone lay antero-medially between the joint margins. In the foot and ankle (Figs. 18 to 20) there were severe changes in the medial malleolus, medial side of the talus, the navicular and possibly the first cuneiform. The knee was explored by dividing the medial ligament. Large bony outgrowths were removed from femur and tibia, the greater part of those from the latter, which was in two portions,

VOL. 38 B, NO. 1, feBruARY 1956 


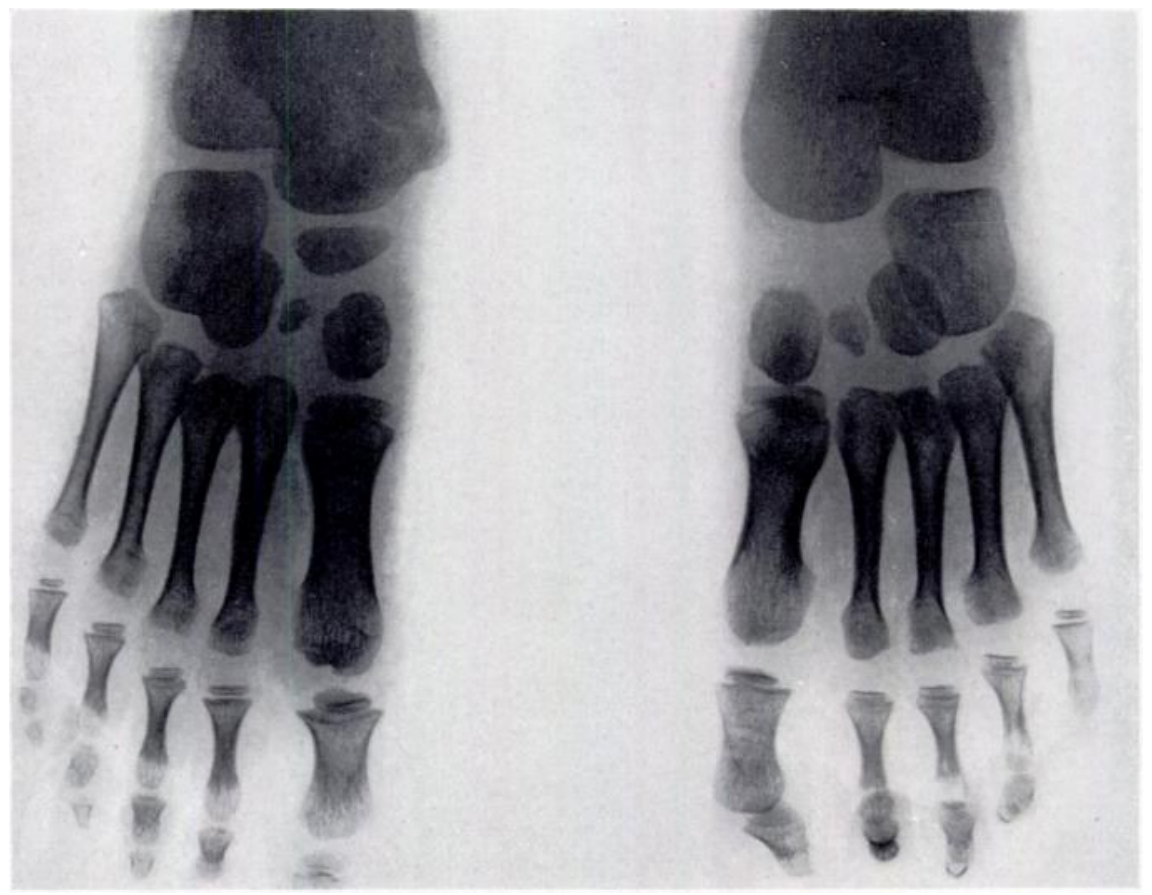

Fig. 16

Case 8-Right foot shows lesion of head of talus, large navicular ossification centre and slight lengthening of first and second metatarsals. Left foot shown for comparison.

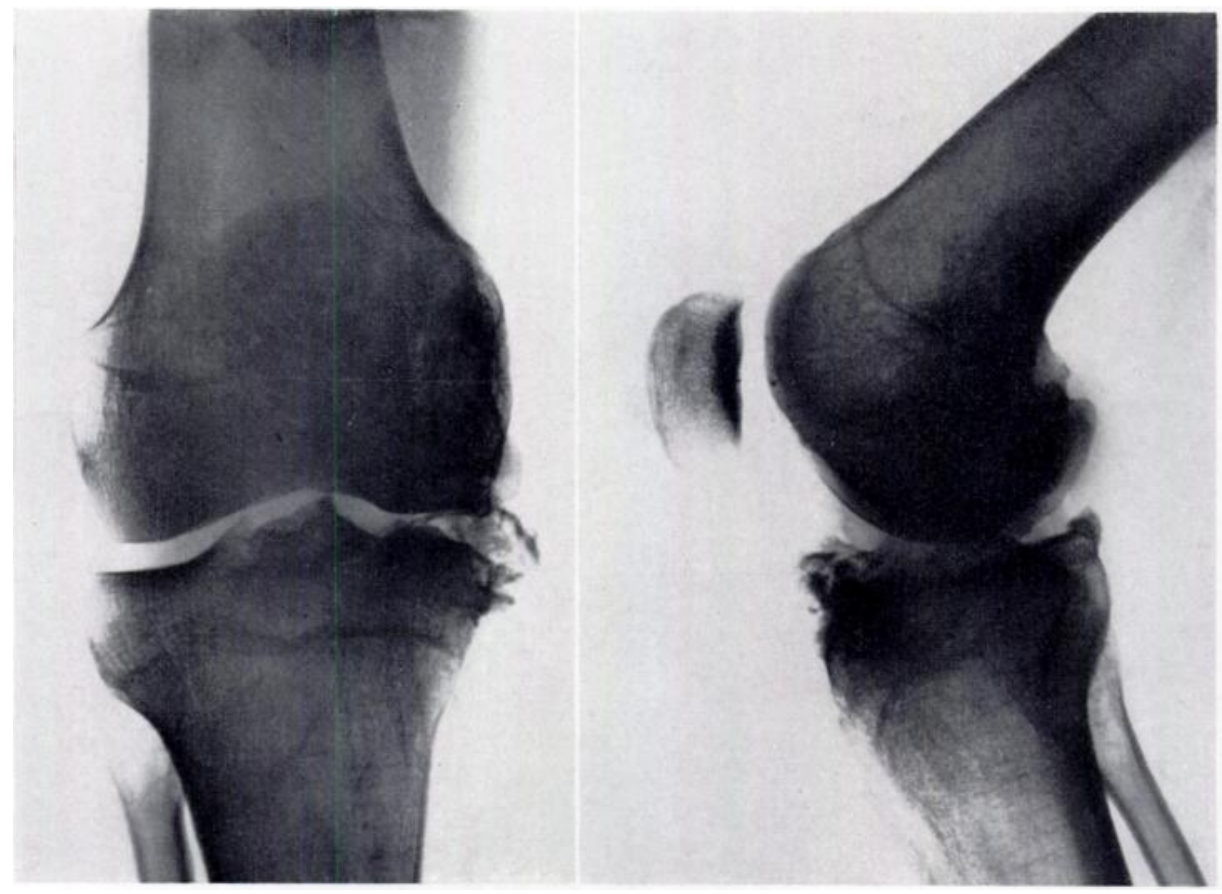

FIG. 17

Case 9-Right knee. The inner sides of both femur and tibia are involved. 


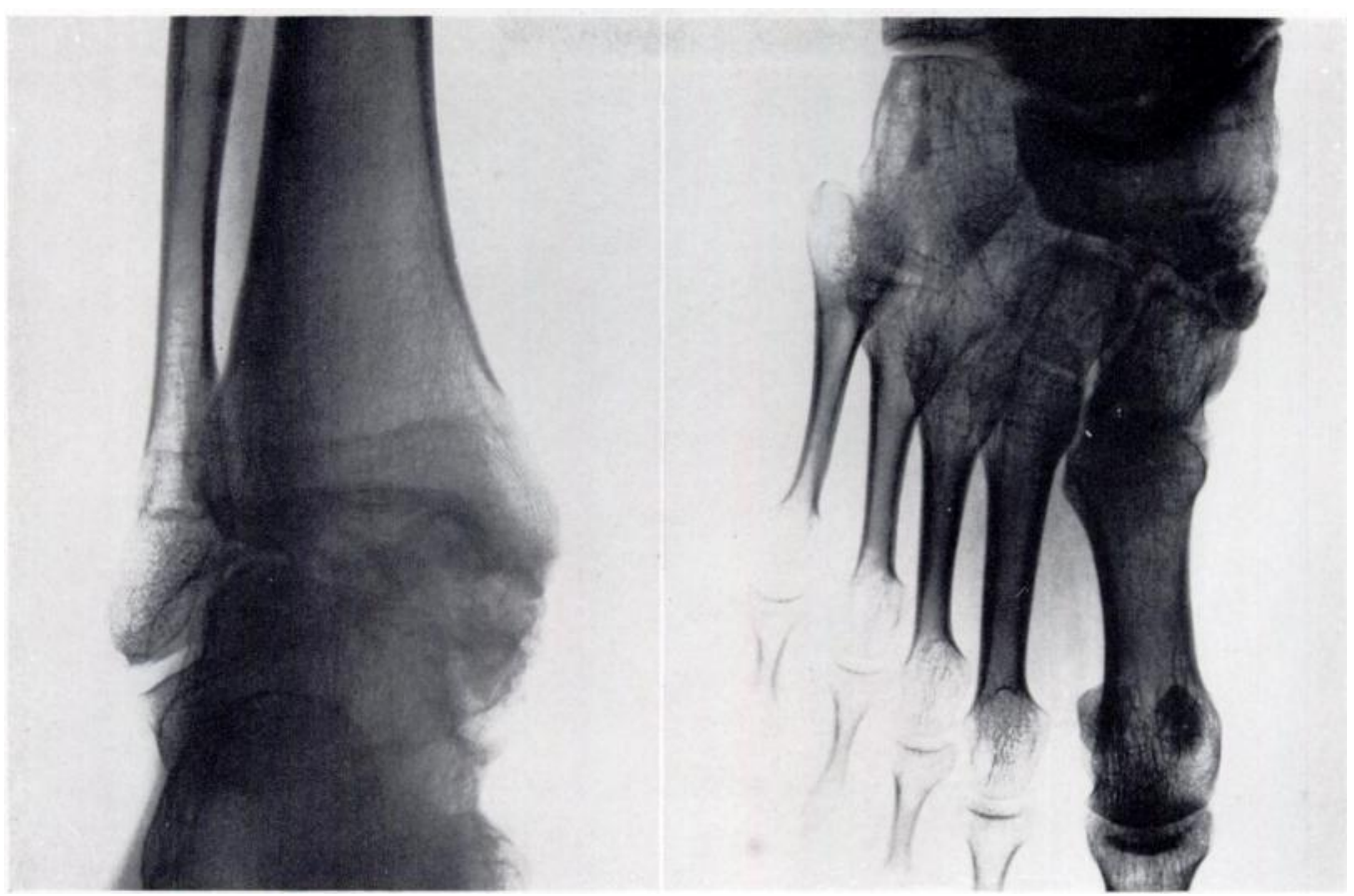

FIG. 18

FIG. 19

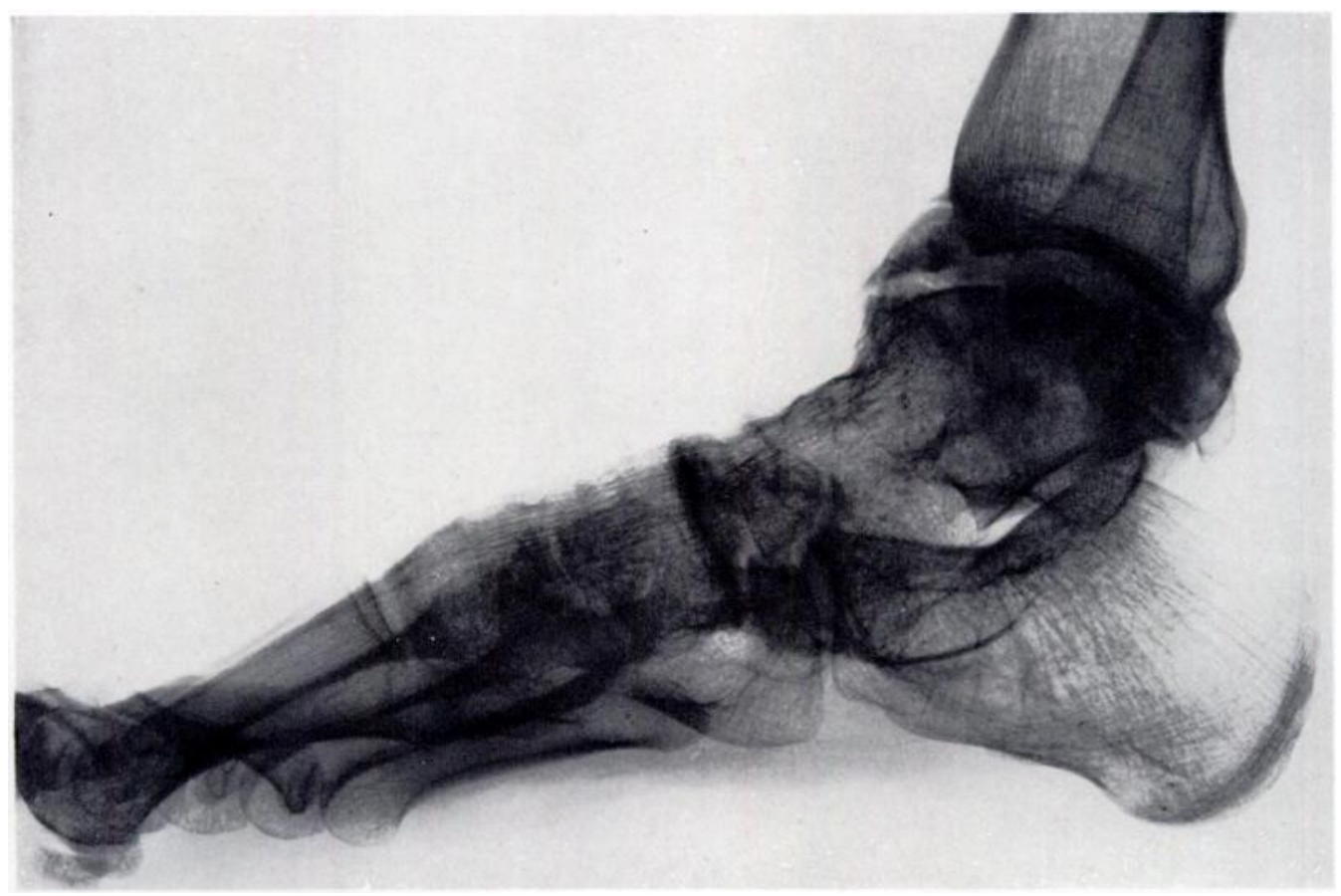

FIG. 20

Case 9-Right ankle and foot. The medial malleolus, talus, navicular and possibly the first cuneiform are affected.

VOL. 38 B, NO. 1, FEBRUARY 1956 


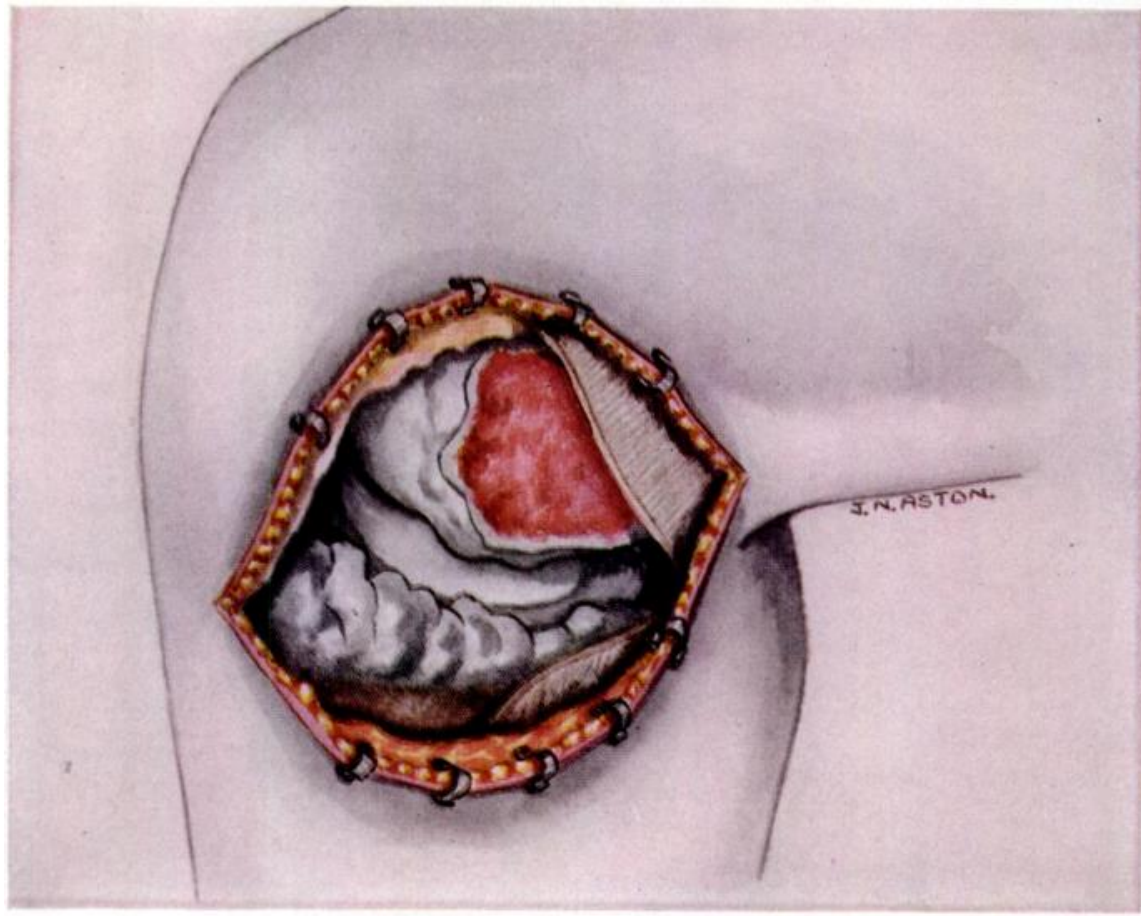

Fig. 21

Case 9-Operative findings. The outgrowth from the femur has been removed. The medial cartilage and tibial mass are still in situ.

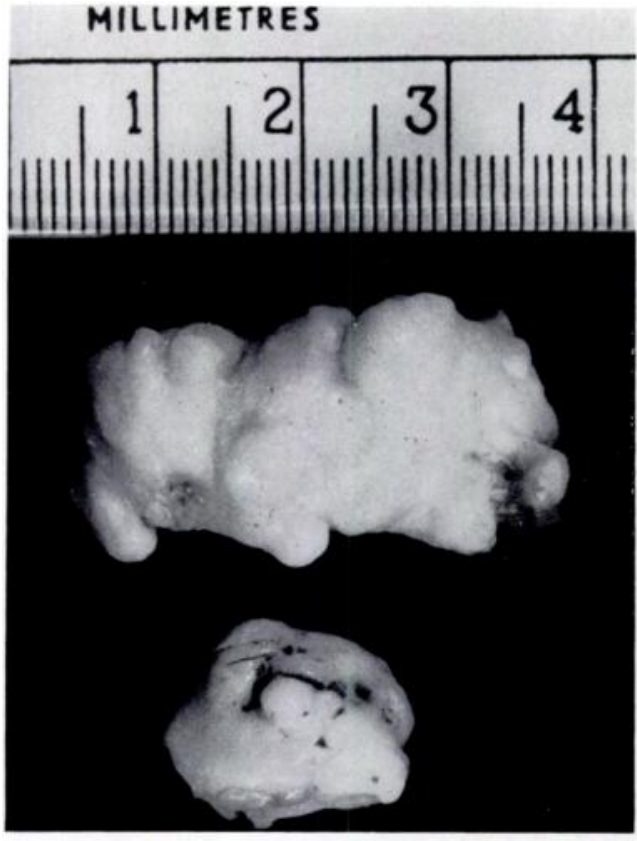

FIG. 22

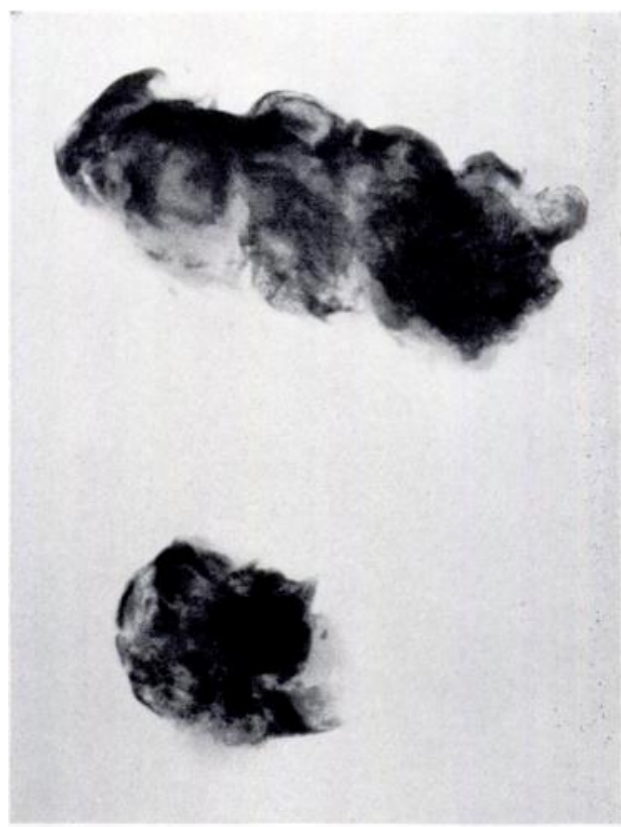

FIG. 23

Case 9. Figure 22-The specimen from the tibia. Figure 23-Radiograph of the specimen. 


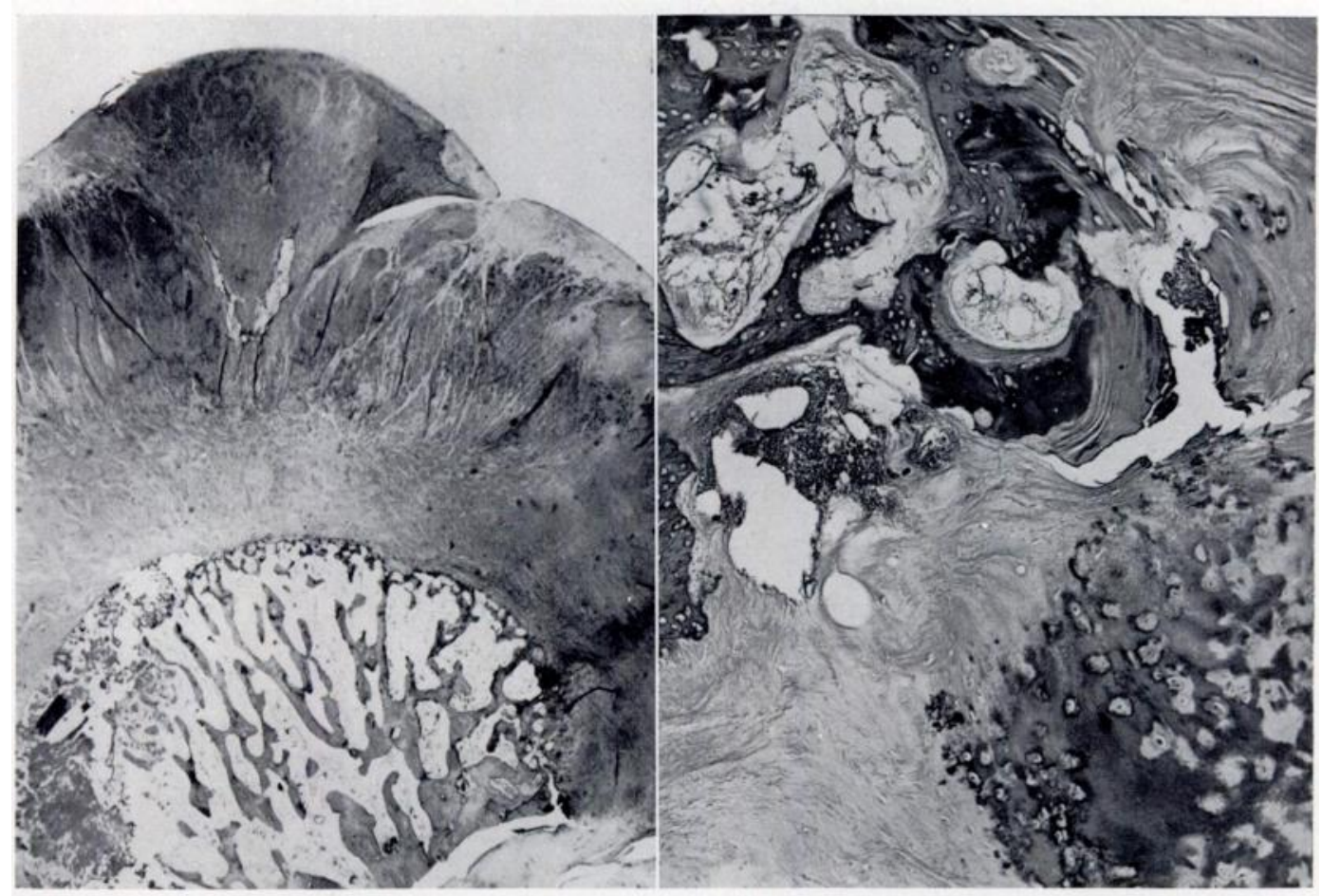

Fig. 24

Fig. 25

Case 9-Photomicrographs of tibial specimens. For description see text. (Fig. 24, $\times 10$; Fig. 25, $\times 75$.)

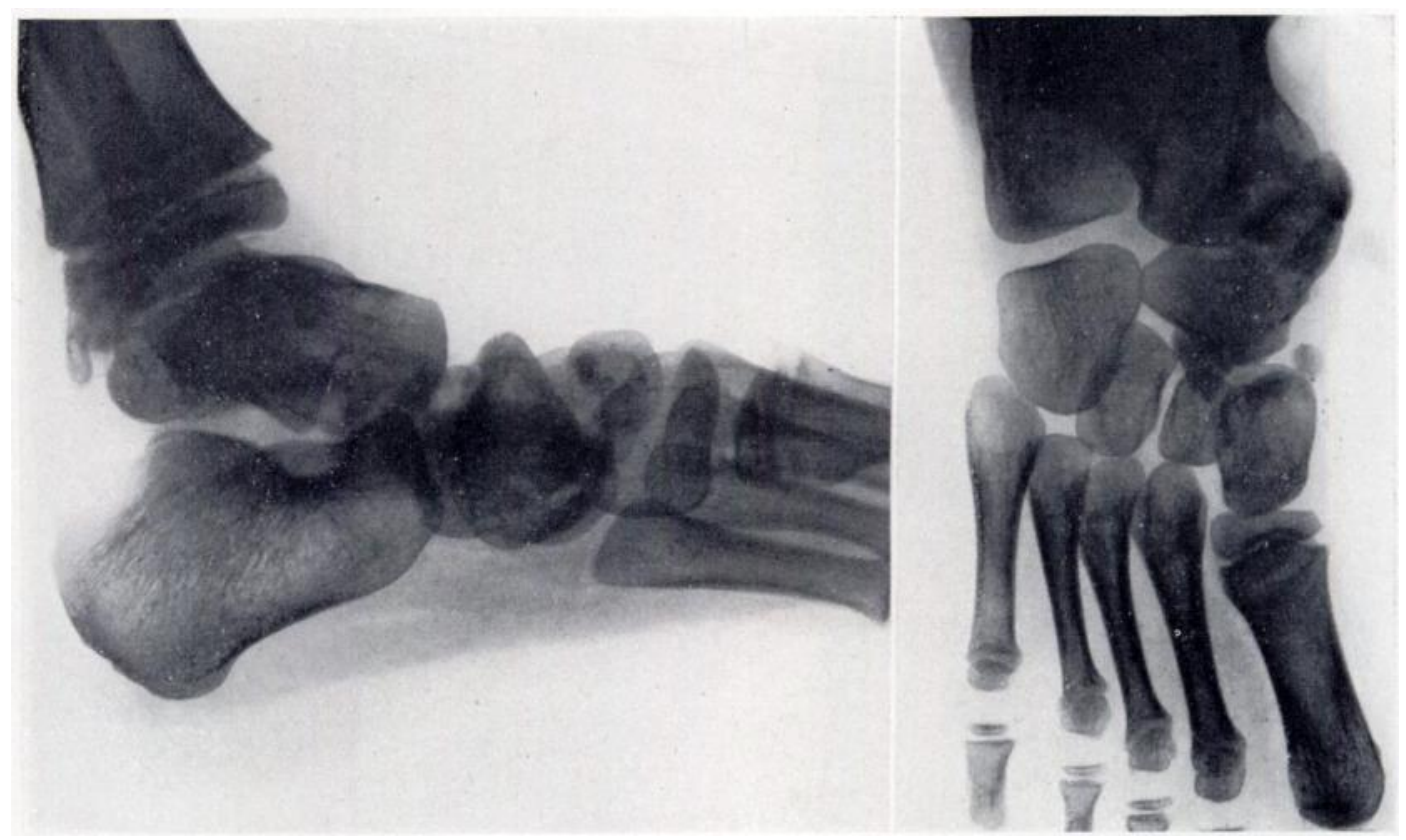

Fig. 26

Case 10-Right foot with lesions of medial malleolus, talus, navicular, and first cuneiform.

VOL. 38 B, NO. 1, FEBRUARY 1956 


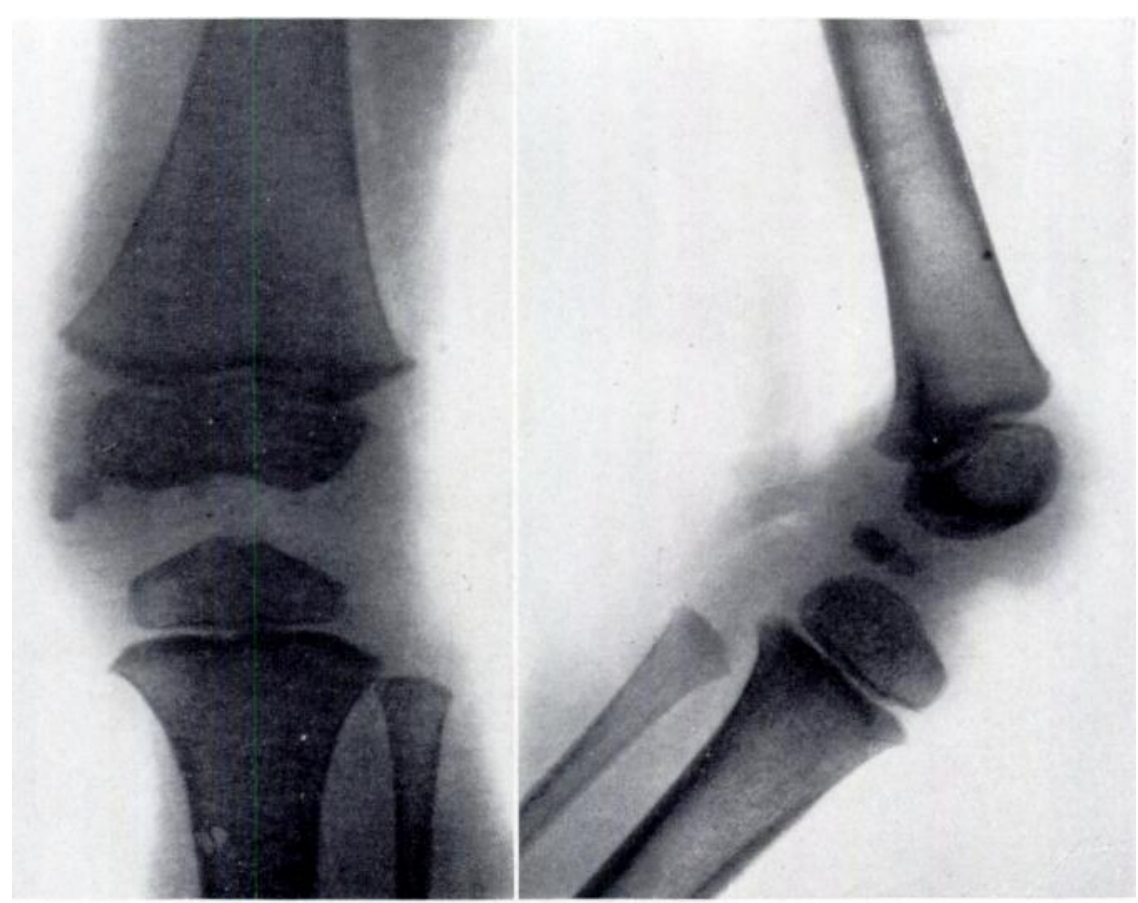

Fig. 27

Case 11-The knee with typical outgrowths from the medial side of the femoral epiphysis.

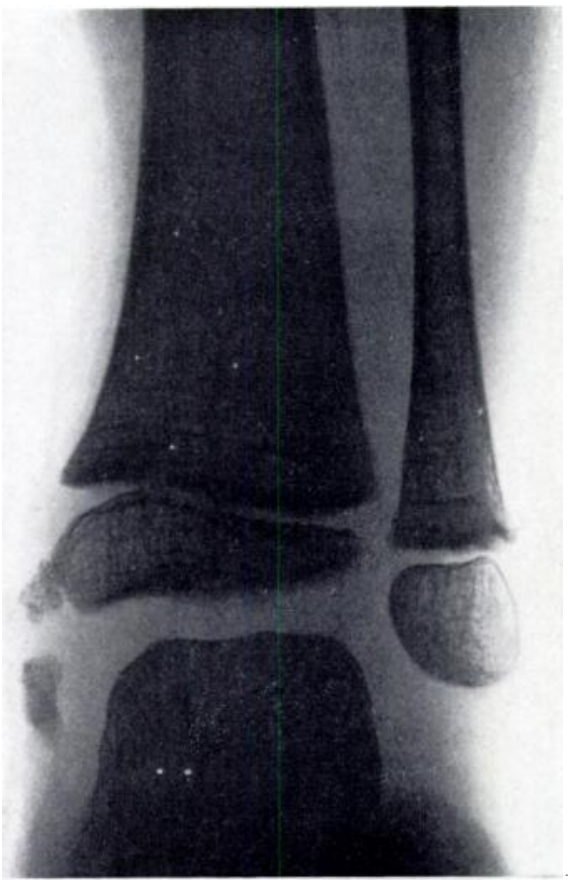

FIG. 28

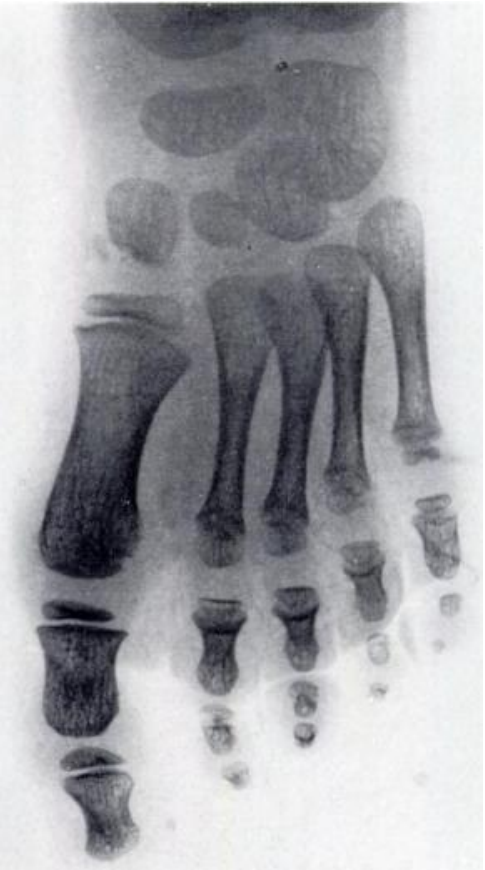

Fig. 29

Case 11. Figure 28-The ankle showing involvement of the medial malleolus. Figure 29-The foot with multiple centres for the first cuneiform. 


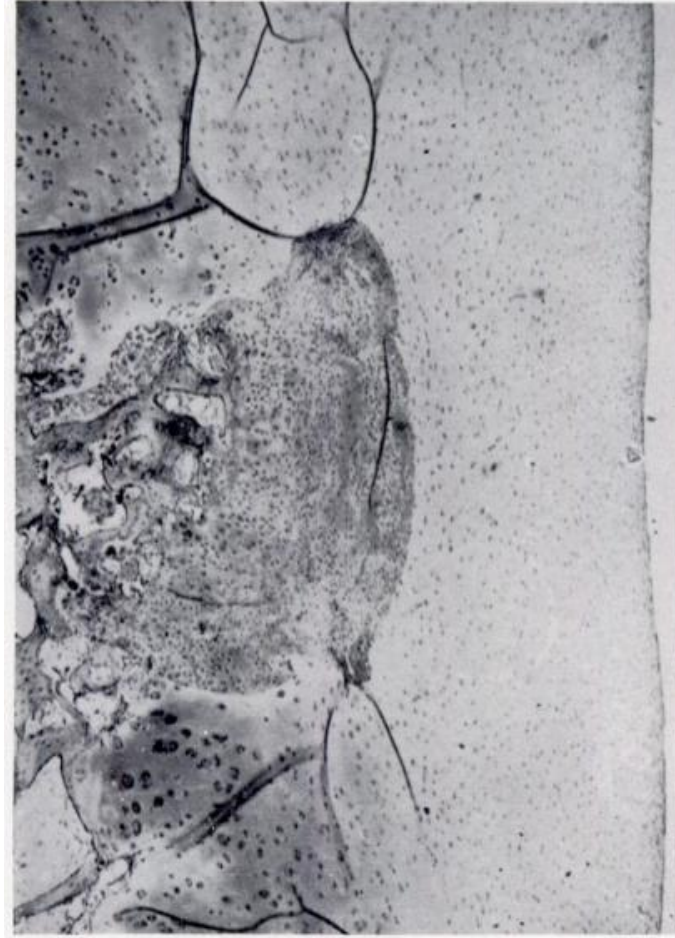

FIG. 30

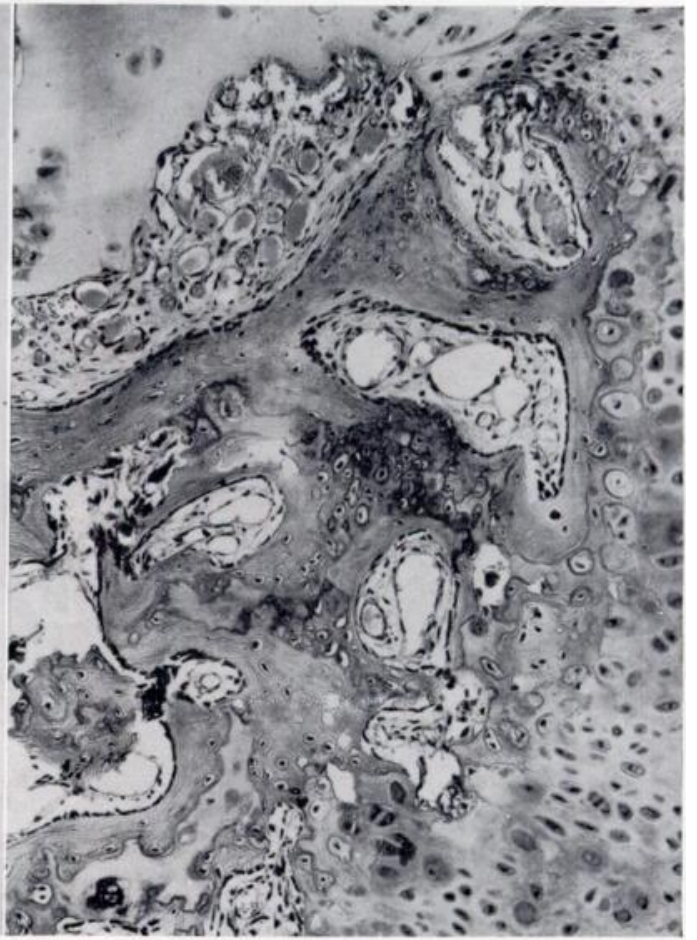

FIG. 31

Case 11. Figure 30-Photomicrograph of specimen from femur. $(\times 25$.$) Figure 31-$ The same. $(\times 90$.

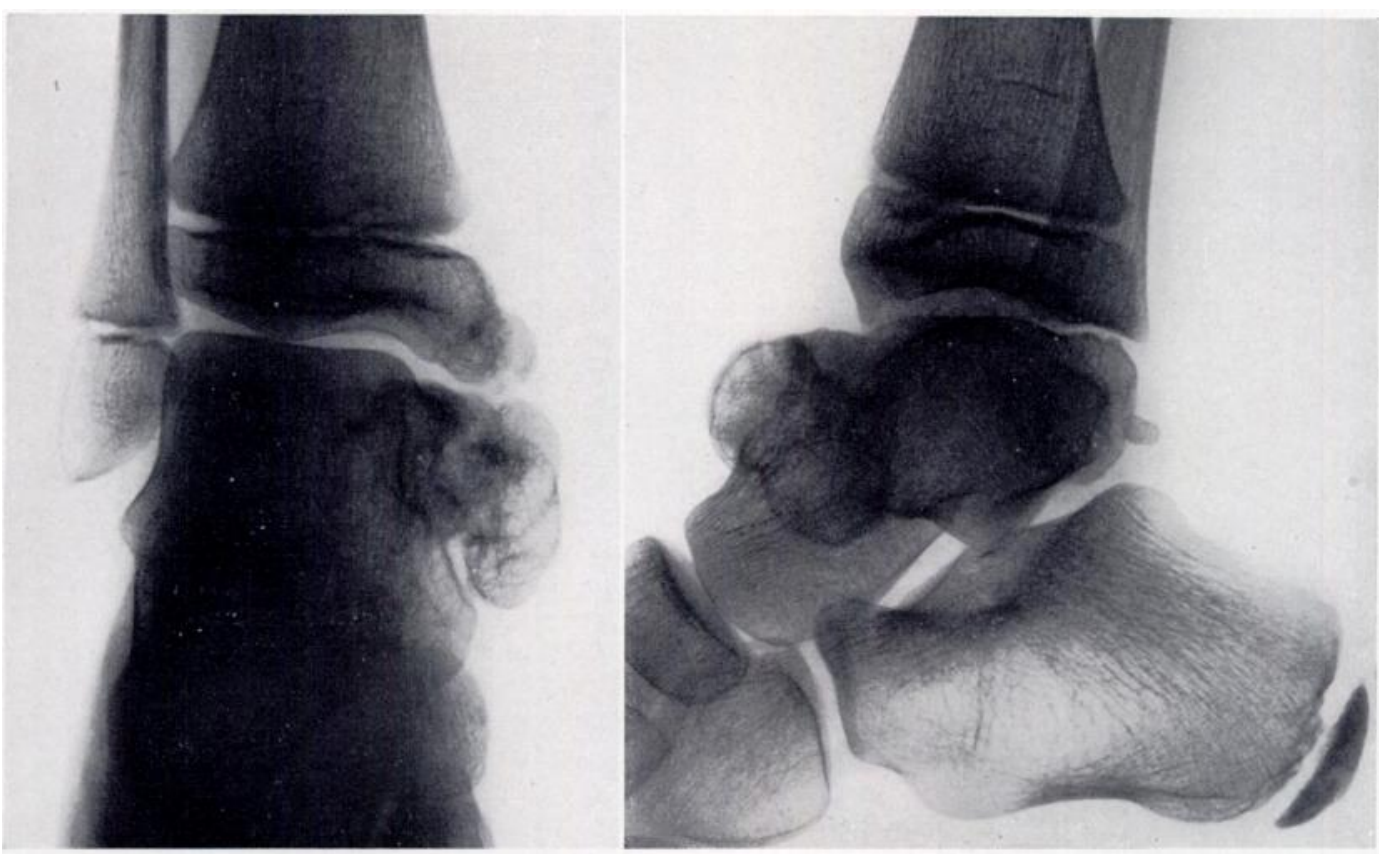

FIG. 32

Case 12-Right ankle showing outgrowths from talus and medial malleolus. 


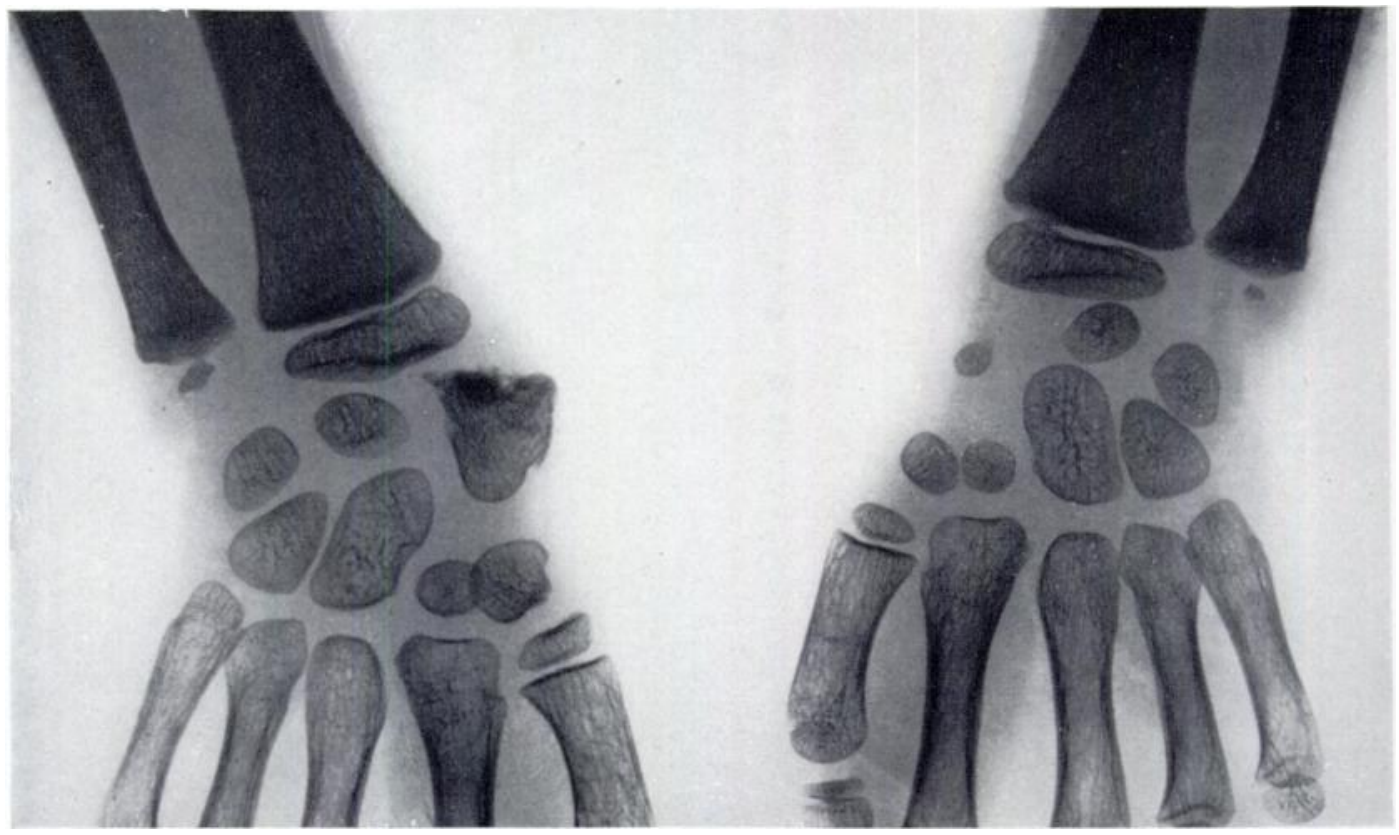

Fig. 33

Case 13-Right wrist showing enlarged distorted scaphoid. Enlarged centres for lunate, trapezium, trapezoid and first metacarpal epiphysis. Left wrist shown for comparison.

lying almost detached in a bed they had made for themselves (Figs. 21 to 23). The semilunar cartilage was excised. Photomicrographs are shown in Figures 24 and 25. Histology showed that all of the bone and much of the cartilage had undergone necrosis, presumably due to deprivation of blood supply when detachment occurred. Degenerative changes of various kinds were present in the surviving

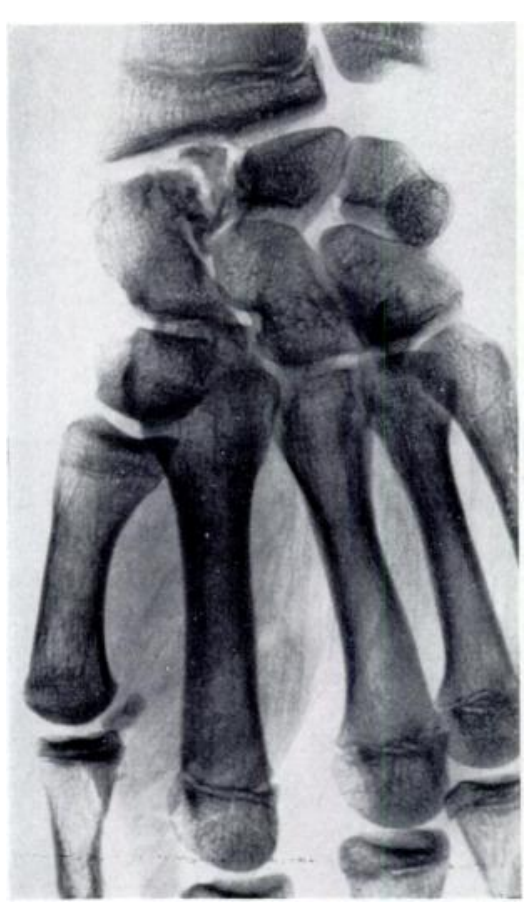

FIG. 34

Case 13-The same eight years later. Elongation of second metacarpal. cartilage: near one surface the fibrillated appearance characteristic of osteoarthritis was seen. The bone was in the form of irregularly round islands which could represent centres of ossification. There was no evidence that ossification was still progressing when necrosis occurred.

Case 10 (reported by courtesy of Mr H. L.-C. Wood)-Girl aged eight. Lump on right ankle noticed first at age of three, slowly increasing since. Limitation of ankle and tarsal movements. A lump could be felt behind the medial malleolus and also on the outer side. She stood with the foot in valgus. There was an inch of wasting of thigh and calf; no inequality in length of limbs. Radiographs showed involvement of medial malleolus, talus, navicular and first cuneiform (Fig. 26).

Case 11 (under care of the author)-Boy aged two years nine months. Six months' history of walking with a stiff left leg, with difficulty in both bending and straightening the knee. With a little force both movements could be performed, in each case with an audible snap on the inner side. The medial femoral condyle was unduly prominent and there was slight genu valgum, equal on the two sides. On exploration the snap was found due to the posterior margin of the medial ligament riding across the protuberance, the removal of which resulted in normal knee movements. Figures 27 to 29 show the lesions in the medial femoral condyle, the medial malleolus and the first cuneiform. There was very slight enlargement of the epiphysis of the first metatarsal. Sections of the specimen (Figs. 30 and 31) showed trabecular bone, the marrow spaces of which were filled with fibro-fatty 


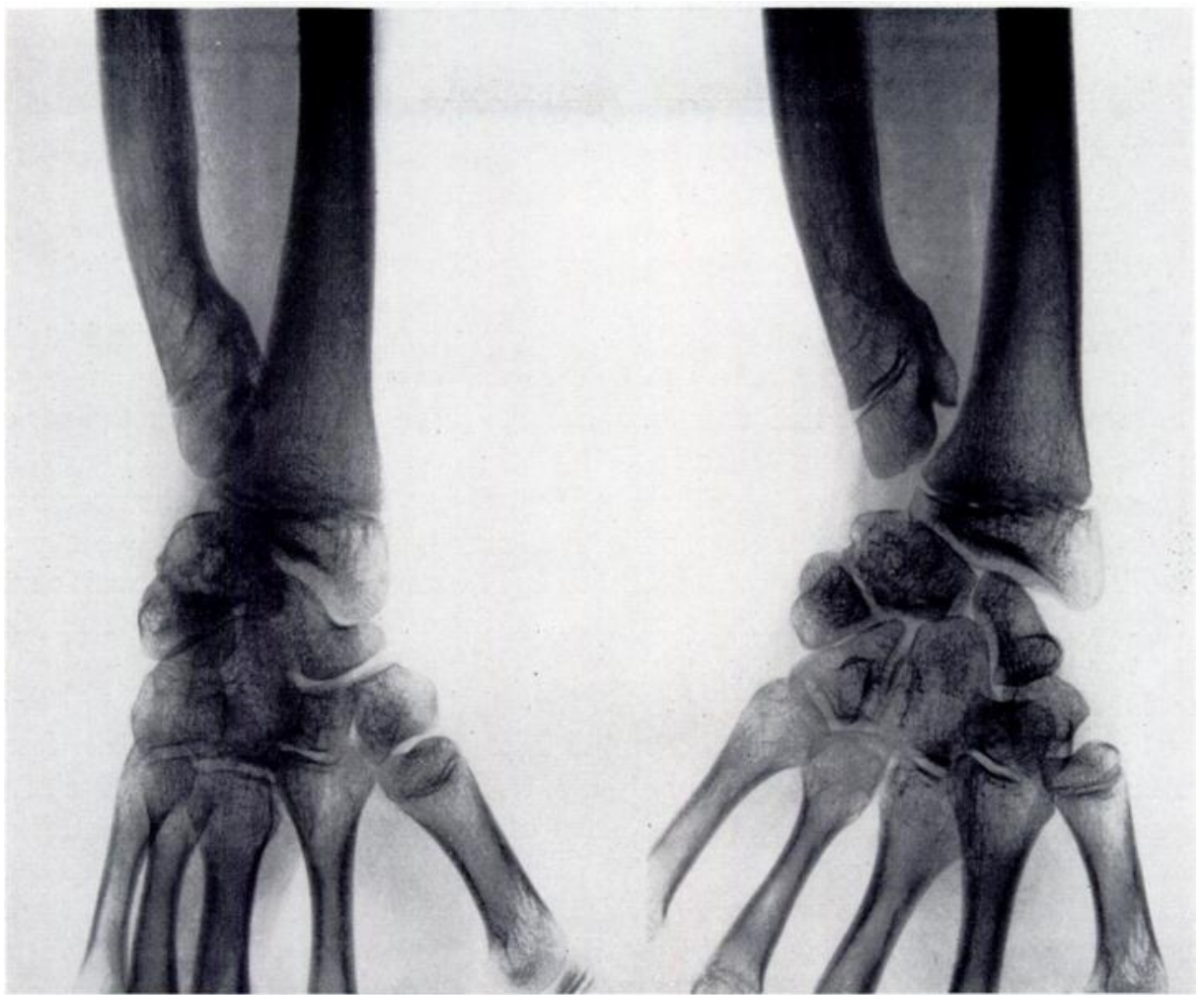

Fig. 35

Case 14-Right wrist showing a deep misshapen ulnar epiphysis, apparently fused laterally, a short bowed ulna and a large irregular lunate affected mainly on its ulnar side.

tissue, covered by a cap of hyaline cartilage, the cells of which were variable in size and were spaced irregularly in clumps.

Case 12 (reported by courtesy of Mr F. C. Dwyer)-Girl aged five. Complained of a lump on the upper and inner surface of the right foot. This increased gradually in size. At the age of eight a bony mass was removed from the talus and the medial malleolus was trimmed. She now walks perfectly normally and there has been no recurrence of the swelling four years later. Radiographs (Fig. 32) showed involvement of the back and front of the medial side of the body of the talus, and enlargement of the medial malleolus.

Case 13 (reported by courtesy of Mr D. Freebody)—Boy aged seven. History of restriction of movement of the right wrist with painless swelling on the radial side increasing gradually over several months. No radial deviation was possible; flexion and extension were slightly limited. Radiographs (Fig. 33) showed a grossly enlarged and distorted scaphoid, the centre for the trapezium enlarged and misshapen, and slight enlargement of those for the lunate, trapezoid and first metacarpal. The patient was kept under observation. Swelling, restriction of movement and weakness gradually increased. Figure 34 shows the appearance eight years later; the second metacarpal was unduly long and massive. At this time the proximal two-thirds of the scaphoid were resected, together with a second fragment apparently arising from the lunate, to which it was attached by fibrous tissue. The wrist made an excellent recovery, with full power, no disability, and only slight restriction of movement.

Case 14 (reported by courtesy of Mr F. C. Dwyer)-Girl aged twelve. First seen aged three because of undue prominence of the right lower ulnar epiphysis. With time the swelling became gradually less conspicuous and she suffers no disability. Radiographs (Fig. 35) showed a short bowed ulna with a deep misshapen lower epiphysis which had apparently fused to the metaphysis on the radial side, a fact presumably responsible for the under-growth and distortion of the shaft. The lunate was enlarged and irregular in texture, the ulnar side being chiefly affected.

VOL. 38 B, NO. 1, FEBRUARY 1956 